University of Tennessee Health Science Center UTHSC Digital Commons

\title{
Gastric Myoelectrical Activity in Patients with Diabetes
}

Sandra Luberata Holmes

University of Tennessee Health Science Center

Follow this and additional works at: https://dc.uthsc.edu/dissertations

Part of the Endocrine System Diseases Commons, and the Nursing Commons

\section{Recommended Citation}

Holmes, Sandra Luberata , "Gastric Myoelectrical Activity in Patients with Diabetes" (2007). Theses and Dissertations (ETD). Paper 123. http://dx.doi.org/10.21007/etd.cghs.2007.0140.

This Dissertation is brought to you for free and open access by the College of Graduate Health Sciences at UTHSC Digital Commons. It has been accepted for inclusion in Theses and Dissertations (ETD) by an authorized administrator of UTHSC Digital Commons. For more information, please contact jwelch30@uthsc.edu. 


\title{
Gastric Myoelectrical Activity in Patients with Diabetes
}

\begin{abstract}
This descriptive, correlational study investigated the associations among gastric myoelectrical activity (GMA), upper gastrointestinal (GI) symptoms, and glucose control. The study also attempted to determine whether any relationship existed between upper GI symptoms, glucose control, age, or length of diagnosis and pattern of GMA identified using electrogastrography (EGG). A total of 25 persons participated in the study. The sample was comprised of 7 healthy controls, 5 patients diagnosed with type 1 diabetes, and 13 patients diagnosed with type 2 diabetes. Electrogastrography was performed for 30 minutes in the fasting state and continued at 30-minute intervals for a total of 1-1/2 hours post-prandially. Data from the fasting, 30-minute post-prandial period, and 120-minute post-prandial periods were analyzed for the study.

Findings of this study support the potential use of EGG as a screening tool in the detection of patterns of GMA in healthy and diabetic individuals. Using EGG, gastric myoelectrical activity can be identified in both healthy controls and patients diagnosed with diabetes. Further studies are needed to generate data that can be used to explain the pathology behind, and relationship between GMA abnormalities, upper GI signs and symptoms, and the lack of glucose control in patients with diabetes.
\end{abstract}

Document Type

Dissertation

Degree Name

Doctor of Philosophy (PhD)

Program

Nursing

Research Advisor

Mona N. Wicks, Ph.D., RN

Keywords

Gastric myoelectrical activity, electrogastrography, diabetes mellitus, motility, gastrointestinal symptoms

Subject Categories

Diseases | Endocrine System Diseases | Medicine and Health Sciences | Nursing 


\title{
GASTRIC MYOELECTRICAL ACTIVITY IN PATIENTS WITH DIABETES
}

\author{
A Dissertation \\ Presentation for \\ The Graduate Studies Council \\ The University of Tennessee \\ Health Science Center
}

In Partial Fulfillment

Of the Requirements for the Degree

Doctor of Philosophy

From The University of Tennessee

\author{
By \\ Sandra Luberata Holmes
}

May 2007 
Copyright (C) Sandra Luberata Holmes, 2007

All rights reserved 


\section{DEDICATION}

This dissertation is dedicated to all of those persons who want to make a difference in the lives of others but don't believe that they can.

You may not think that your contribution is important,

but to someone you are a hero. 


\section{ACKNOWLEDGEMENTS}

I would like to express my sincerest appreciation to my dissertation advisor, Dr. Mona N. Wicks, for her guidance, direction, time, patience, and encouragement during the preparation and writing of this dissertation. I would like to thank my committee members, Dr. Donna Hathaway, Dr. Ann Cashion, Dr. Margaret Heitkemper, Dr. Jim Wan, Dr. Babajidi Familoni, and Dr. Pedro Velasquez, for their guidance during this project. I also wish to extend a special thanks to the technical support staff at Biopac and Dr. Senqi Hu for their technical assistance.

To my family and friends, Lillie Holmes, Della Drummond, Wanda Gilbert, Lee Davis, Jacqueline Harbin, and the staff at the HELP Center, thanks for everything! I could not have made it through without all of your help. I would also like to thank my extended family at Golden Gate Cathedral Full Gospel Baptist Church for the support and prayers that kept me strong and encouraged me to complete this endeavor.

I also wish to acknowledge the funding support of the Southern Regional Education Board (SREB) and Beta Theta Chapter-at-Large of Sigma Theta Tau International Nursing Society. 


\begin{abstract}
This descriptive, correlational study investigated the associations among gastric myoelectrical activity (GMA), upper gastrointestinal (GI) symptoms, and glucose control. The study also attempted to determine whether any relationship existed between upper GI symptoms, glucose control, age, or length of diagnosis and pattern of GMA identified using electrogastrography (EGG).
\end{abstract}

A total of 25 persons participated in the study. The sample was comprised of 7 healthy controls, 5 patients diagnosed with type 1 diabetes, and 13 patients diagnosed with type 2 diabetes. Demographic data, a health history, blood sampling, and assessment of historical and current upper GI symptoms were obtained. Electrogastrography was performed for 30 minutes in the fasting state and continued at 30-minute intervals for a total of 1-1/2 hours post-prandially. Data from the fasting, 30-minute post-prandial period, and 120-minute post-prandial periods were analyzed for the study.

For research question one, non-significant $\mathrm{p}$ values were confirmed during fasting $(\mathrm{p}=.14)$ and 120 -minutes post-prandial $(\mathrm{p}=.11)$. A significant $\mathrm{p}$ value was noted at 30 minutes post-prandial $(p=.04)$. This suggests that no difference exist between patterns of GMA in healthy subjects and patients with diabetes except during the period immediately after eating. No significant differences in the pattern of GMA were identified in type 1 versus type 2 diabetic patients during any sampling period $(\mathrm{p}=.81, .49$, and .88 , respectively).

Research question 2 looked at GMA during 3 periods. At the end of the fasting period (period 1), there were 7 patients with normogastria, 10 with bradygastria, and 1 
with tachygastria. The bradygastric group reported greater mean scores for symptom presence and severity historically and during the fasting period on all upper GI signs and symptoms. During period 1, mean scores for satiety on the TSS scale were the only variable yielding any significant result $(\mathrm{p}=.04)$. For this sample, no relationship was found between the three patterns of GMA and acute blood glucose, metabolic control, age, or length of diagnosis in patients with diabetes who were fasting. During the first post-prandial period (30 minutes post meal; period 2), 4 subjects were normogastric, 7 were bradygastric, and 7 were tachygastric. There were no significant differences found between the distributions of scores for the variables under study and patterns of GMA. During the 120-minute post prandial period (period 5), 6 subjects were normogastric, 7 were bradygastric, and 5 were tachygastric. There were no significant differences found between the distributions of mean scores for the variables under study and patterns of GMA.

In conclusion, findings of this study support the potential use of EGG as a screening tool in the detection of patterns of GMA in healthy and diabetic individuals. Using EGG, gastric myoelectrical activity can be identified in both healthy controls and patients diagnosed with diabetes. Further studies are needed to generate data that can be used to explain the pathology behind, and relationship between GMA abnormalities, upper GI signs and symptoms, and the lack of glucose control in patients with diabetes. 


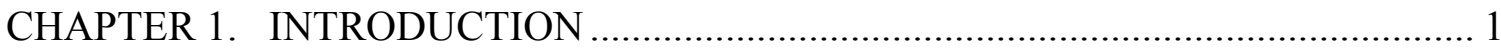

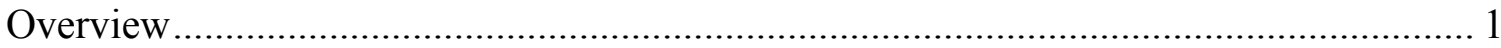

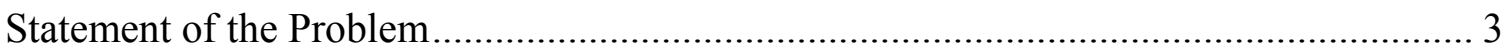

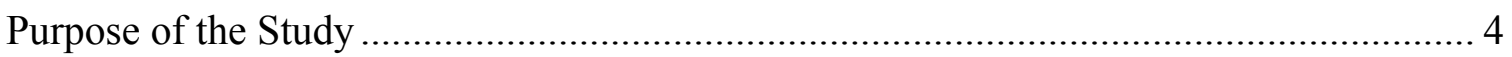

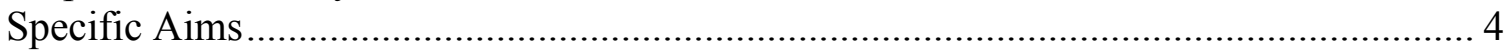

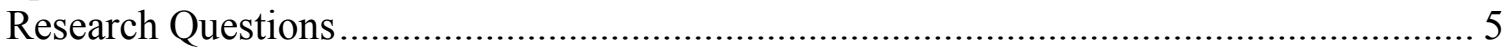

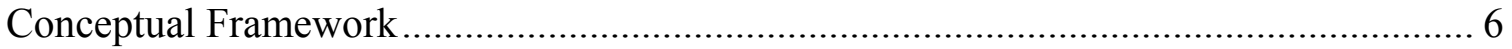

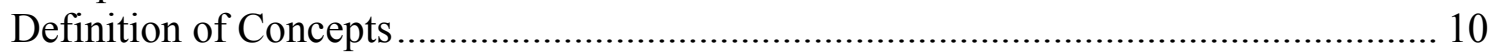

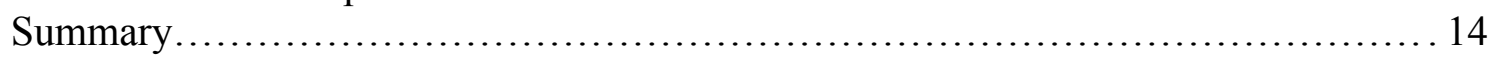

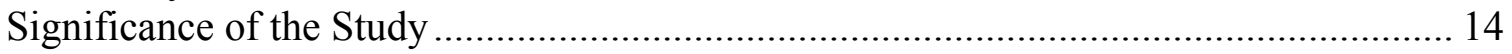

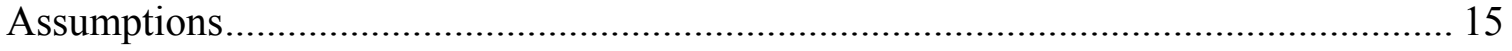

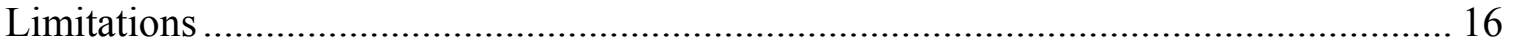

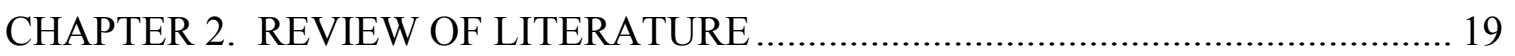

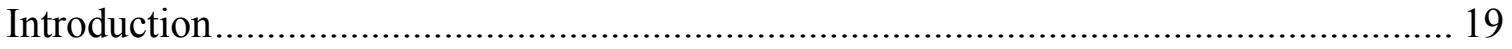

Pathophysiology of Diabetes Mellitus .................................................................... 19

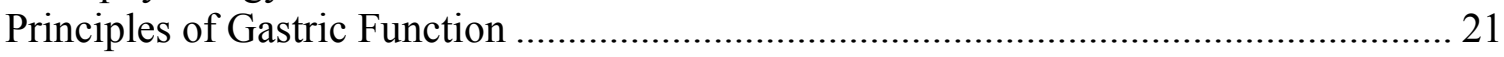

Gastric Complications in Patients with Diabetes............................................................ 25

Gastric Myoelectrical Activity and Electrogastrography .............................................. 27

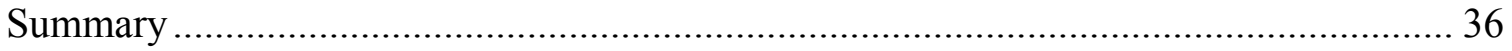

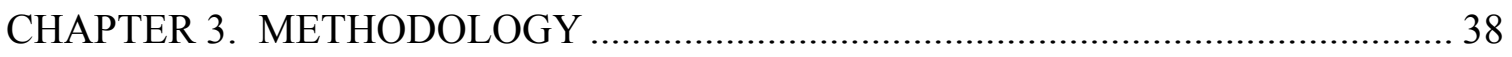

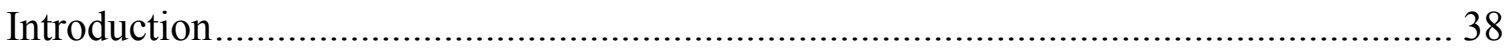

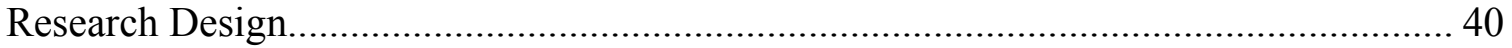

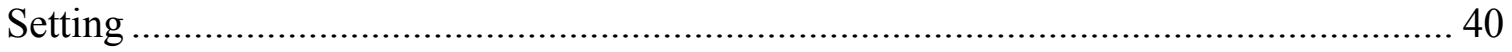

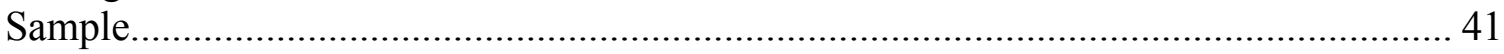

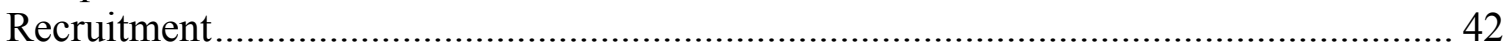

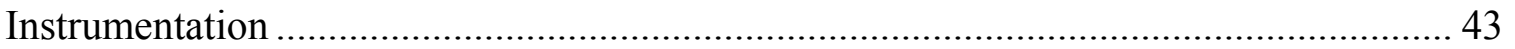

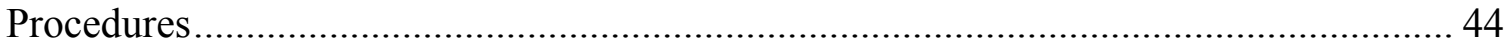

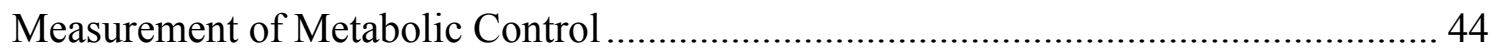

Measurement of Upper Gastrointestinal Symptoms .................................................... 46

Measurement of Gastric Myoelectrical Activity........................................................... 47

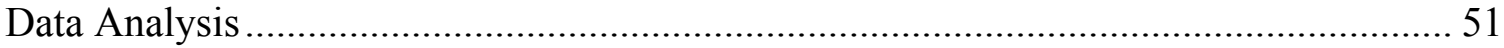

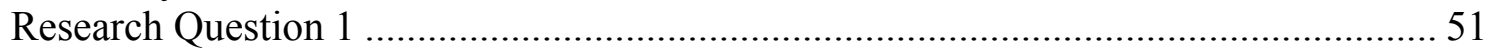

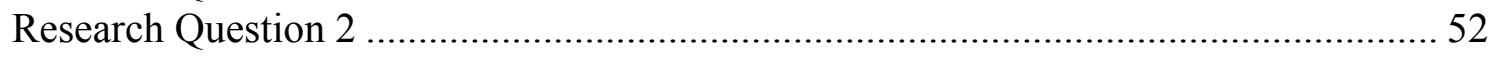

Protection of Human Subjects ............................................................................. 53

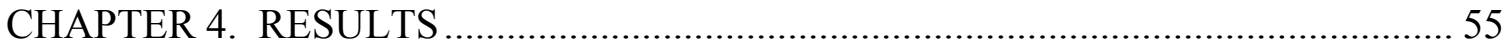




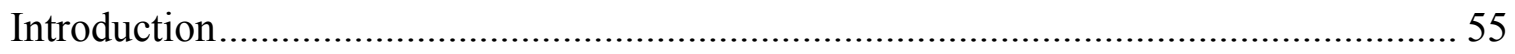

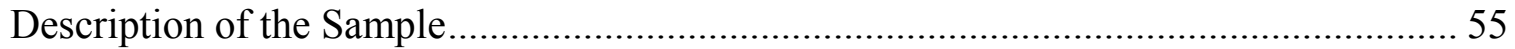

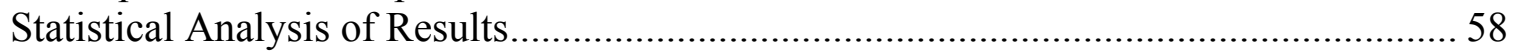

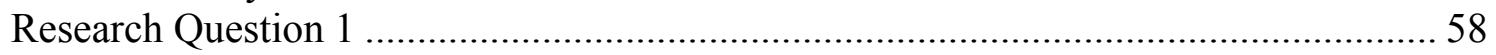

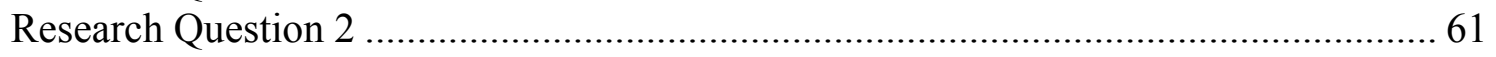

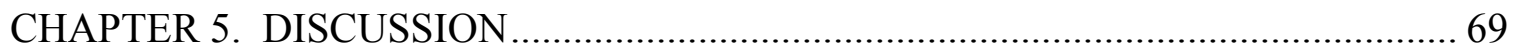

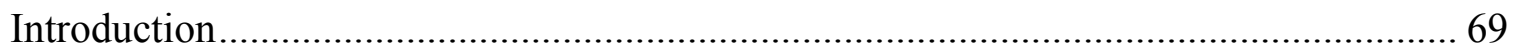

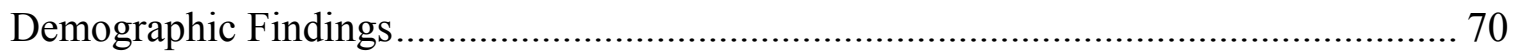

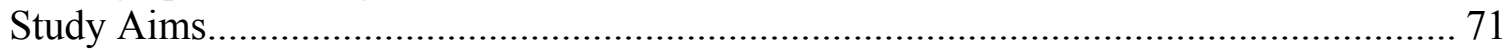

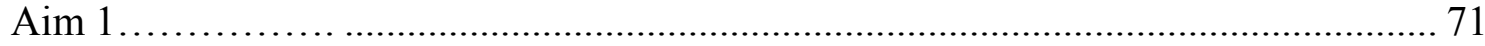

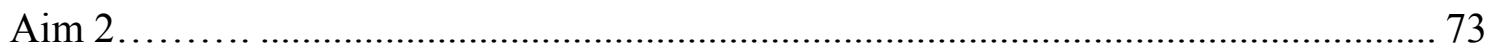

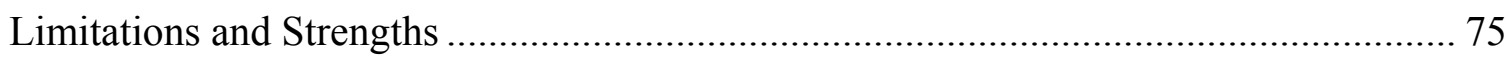

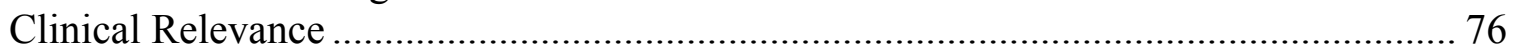

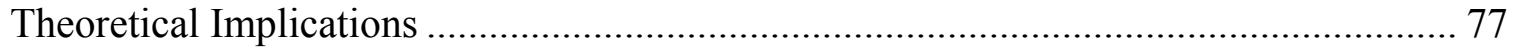

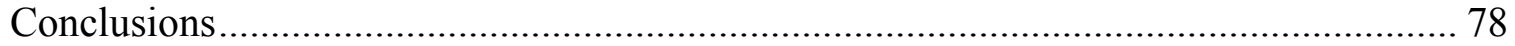

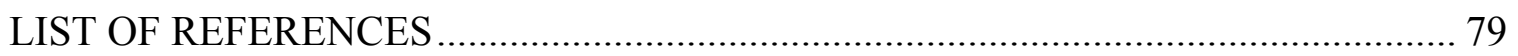

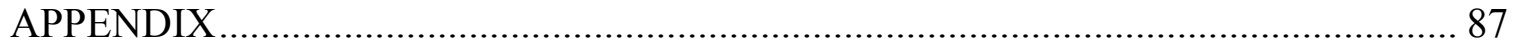

Appendix A. Institutional Review Board Approval Letter............................................... 88

Appendix B. Patient Information and Informed Consent Form ....................................... 90

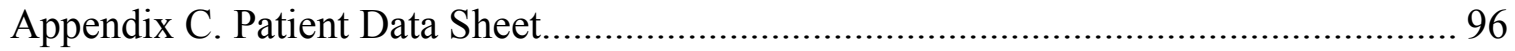

Appendix D. Flow Diagram of Testing Procedure ………............................................ 98

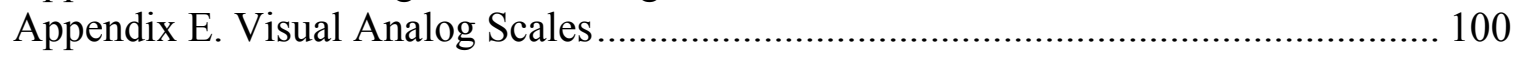

Appendix F. Total Symptom Scale ............................................................................. 107

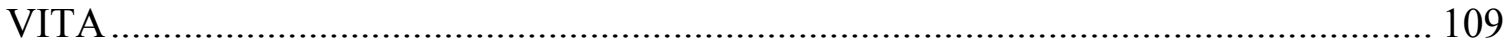




\section{LIST OF TABLES}

Table 1. Descriptive Statistics for Study Participants by Controls and Patients with Type 1 and Type 2 Diabetes

Table 2. Patterns of Gastric Myoelectrical Activity in Healthy Controls versus Diabetic Patients by Testing Period ...............................60

Table 3. Patterns of Gastric Myoelectrical Activity in Type 1 versus Type 2 Diabetic Patients by Testing Period 62

Table 4. Mean Scores for Patterns of Gastric Myoelectrical Activity and Study Variables in Patients with Diabetes Mellitus Who Were Fasting (Period 1)

Table 5. Mean Scores for Patterns of Gastric Myoelectrical Activity and Study Variables in Patients with Diabetes Mellitus Who Were 30Minutes Post-Prandial (Period 2)

Table 6. Mean Scores for Patterns of Gastric Myoelectrical Activity and Study Variables in Patients with Diabetes Mellitus Who Were 120-Minutes Post-Prandial (Period 5) 


\section{LIST OF ABBREVIATIONS}

Ach Achetylcholine

ANS

Autonomic Nervous System

BGM Blood Glucose Monitoring

BMI Body Mass Index

CNS Central Nervous System

cpm. Cycles Per Minute

DF Dominant Frequency

DFIC Dominant Frequency Instability Coefficient

EGG. Electrogastrography

ENS Enteric Nervous System

GHB. Glycosolated Hemoglobin GH/IGF-1 Growth Hormone/Insulin-like Growth Factor-1

GI. Gastrointestinal GMA Gastric Myoelectrical Activity $\mathrm{HbAlc}$ Hemoglobin A1c

HELP Center. Center for Health Evaluation and Lifestyle Promotion MMC Migrating Motor Complex

PNS. Parasympathetic Nervous System PR Power Ratio QOL Quality of Life SNS .Sympathetic Nervous System 
TSS. Total Symptom Score

UTB. .University of Tennessee Bowld Hospital UTHSC ..University of Tennessee Health Science Center VAS. Visual Analog Scale 


\section{CHAPTER 1. INTRODUCTION}

\section{Overview}

The gastrointestinal (GI) system has an underlying pattern of electrical activity much like the one in the cardiac system that controls its contractile and propulsive activity. Gastric myoelectrical activity (GMA) originates in the body of the stomach and normally propagates toward the pylorus at a rate of three cycles per minute (cpm; Parkman, Hasler, Barnett, \& Eaker, 2003). Changes in GMA affect gastric motility and gastric emptying. The resulting dysfunction leads to alterations in the process of digestion. These alterations are manifested as GI signs and symptoms such as nausea, vomiting, anorexia, early satiety, bloating, and abdominal pain. In persons with diabetes mellitus, altered GMA affects digestion of nutrients and drugs, further complicating the ability to achieve and maintain normoglycemia. Mismatches in circulating insulin and nutrient availability contribute to problems with maintaining glucose control and increase the progression of diabetes complications. The older the person with diabetes is and the longer the length of diagnosis, especially if poorly controlled, the more likely complications are to exist. These factors increase the burden of diabetes care and decrease the quality of life (QOL) of persons with diabetes. Identification of changes or abnormalities in patterns of GMA in relation to GI signs and symptoms, glucose control, age, and length of diagnosis could be used to direct interventions that could halt or retard the progression of diabetes complications and improve the QOL experienced by this population. 
Patterns of GMA can be assessed using electrogastrography (EGG).

Electrogastrography is a simple, noninvasive tool that can be used to provide valid information about changes in patterns of GMA prior to manifestations of actual signs and symptoms of altered function. Electrogastrography captures GMA cutaneously with little preparation, is more comfortable, and less burdensome for patients than other test of GI function. The tool is easy to use and requires only a short period to obtain data. Although it has been available for some time, EGG has developed relatively slowly since its first application by Alvarez (1922) in 1921. Difficulty in overcoming problems related to capturing and analyzing data had to wait until technological advances could provide more valid and reliable data. Continued study of the GI system and improvements in biomedical instrumentation, have increased EGG's ability to distinguish patterns of GMA in healthy individuals from those with certain diseases or conditions (Chen, Lin, Sarosiek, \& McCallum, 1996; Familoni, 1994; Kim, Ming, \& Camilleri, 2000; Pfaffenbach, Adamek, Kuhn, \& Wegener, 1995; Sanmiguel, Mintchev, \& Bowes, 1998). Examining EGG patterns of GMA in specific disease states will help to determine the clinical utility of EGG. For these reasons, the present study focuses on examining the ability of EGG to detect GMA and correlating EGG results with upper GI signs and symptoms, acute blood glucose levels, and long-term metabolic control in patients with diabetes mellitus. The use of EGG in the clinical setting may provide diagnostic information that can assist in identifying pathology behind problems with gastric function. Electrogastrography can also be used for monitoring GMA and has the potential for determining abnormalities that may precede serious complications of diabetes, providing time to develop and institute specific treatment options. 
Studies over the past 20 years evaluating GMA in persons with diabetes have yielded key information as well as conflicting results. Some investigators report significant relationships between or among gastric rhythm, symptom presence, and level of metabolic control (Cucchiara et al., 1998; Koch, Stern, Stewart, \& Vasey, 1989; Mantides et al., 1997; Mayaudon et al., 1999; Soykan, Lin, Sarosiek, \& McCallum, 1999) in persons with type 1 diabetes. Results of studies of GMA in persons with type 2 diabetes (Gad-el-Hak \& Baker, 2001; Mathur, et al, 2001; Qi, Luo, \& Wang, 2002) provided additional insight and knowledge into the complexity of GMA, GI symptoms, and metabolic control in this group of patients. Other studies (El-Salhy \& Sitohy, 2001; Jebbink et al., 1994; Pfaffenbach et al., 1995) were unable to distinguish significant differences in gastric rhythm, symptoms, and blood glucose measures between persons with type 1 or type 2 diabetes and healthy controls. Methods used to study gastric dysrhythmias and their relationship to gastric symptoms and metabolic control in patients with diabetes have not been performed consistently. This pilot study seeks to assess and describe patterns of GMA in patients with diabetes mellitus controlling for multiple variables, and to determine if specific patterns of GMA correspond with upper GI signs and symptom presence and severity, acute blood glucose levels, long-term glucose (metabolic) control, age, or length of diagnosis in patients with diabetes mellitus.

\section{Statement of the Problem}

A large percentage of patients with diabetes report an increased incidence of GI signs and symptoms and inability to gain and/or maintain glucose control. Alterations in the digestive process contribute to these problems. Electrical, neuronal, and chemical 
(hormonal) mechanisms must work in concert for digestion to occur normally. Because of the complexity of the digestive process, and inconsistencies in previous studies, further research under controlled conditions is needed to identify the relationship between GMA, GI signs and symptoms, glucose control, age and length of diagnosis, and to determine the actual significance of the information obtained. Therefore, this study was proposed.

\section{Purpose of the Study}

The purpose of this pilot study was to assess and describe GMA in patients with diabetes mellitus using EGG. Additionally, the study sought to determine if specific patterns of activity corresponded with levels of symptom presence and severity, acute blood glucose levels, level of long-term metabolic control, age, or length of diagnosis during specific periods during the digestive process. This study's results were based on findings made during the fasting, 30-minutes post prandial, and 120-minutes post prandial periods.

\section{Specific Aims}

Specific aims of this study were to 1) characterize the pattern of GMA in patients with diabetes, and 2) describe the relationships among patterns of GMA, symptom presence and severity, acute blood glucose level, long-term metabolic control, age, and length of diagnosis in patients with diabetes. 


\section{Research Questions}

Two research questions were addressed by the present study:

1. Research Question 1: What patterns of GMA can be assessed using EGG in patients with diabetes?

1a. What are the differences in patterns of GMA in healthy individuals versus diabetic patients?

1b. What are the differences in patterns of GMA in patients with type 1 versus type 2 diabetes?

2. Research Question 2: What is the relationship of patterns of GMA with upper GI symptoms, acute blood glucose measurement, metabolic control, age, and length of diagnosis in patients with diabetes mellitus?

2a. What is the relationship of patterns of GMA with upper GI symptoms, acute blood glucose measurement, metabolic control, age, and length of diagnosis in patients with diabetes mellitus who are fasting?

2b. What is the relationship of patterns of GMA with upper GI symptoms, acute blood glucose measurement, metabolic control, age, and length of diagnosis in patients with diabetes mellitus who are 30 minutes post-prandial?

2c. What is the relationship of patterns of GMA with upper GI symptoms, acute blood glucose measurement, metabolic control, age, and length of diagnosis in patients with diabetes mellitus who are 120 minutes post-prandial? 


\section{Conceptual Framework}

A conceptual framework serves three important purposes: it clarifies the concepts on which the study is built, identifies and states assumptions underlying the study, and specifies relationships among concepts (Woods \& Cantanzaro, 1988). The conceptual framework (Figure 1) proposed in this study provided structure and guided the organization of the study.

Diabetes mellitus is a complicated disease, requiring a comprehensive treatment plan that includes provider and patient contributions, in order to achieve the goals of establishing good metabolic control, reducing complications, and maintaining an acceptable QOL. Complications of diabetes arise as a result of persistently high blood glucose levels, a factor that can be treated effectively (Davidson, 1998; Huether \& Tomkey, 1997; Kahn \& Porte, 1997; Krall \& Beaser, 1989; Palmer \& Lenmark, 1997). Maintenance of glucose control is one of the most important aspects of diabetes care. Acute blood glucose levels must be kept at normal, or near normal levels, in order to achieve consistent overall metabolic control. Despite following the prescribed regime, some individuals are still unable to gain adequate metabolic control. Changes in the normal digestive pattern occurring in $30 \%$ to $50 \%$ of patients with diabetes, may contribute to, as well as result in, problems with maintaining metabolic control (Enck \& Frieling, 1997; Horowitz \& Fraser, 1994; Horowitz, Wishart, Jones, \& Hebbard, 1996; Koch, 1999; Rothstein, 1990). In those diabetic patients who experience changes in digestive activity, symptoms reflecting alterations in normally coordinated movement of nutrients through the GI tract such as nausea, vomiting, abdominal pain, anorexia, early 


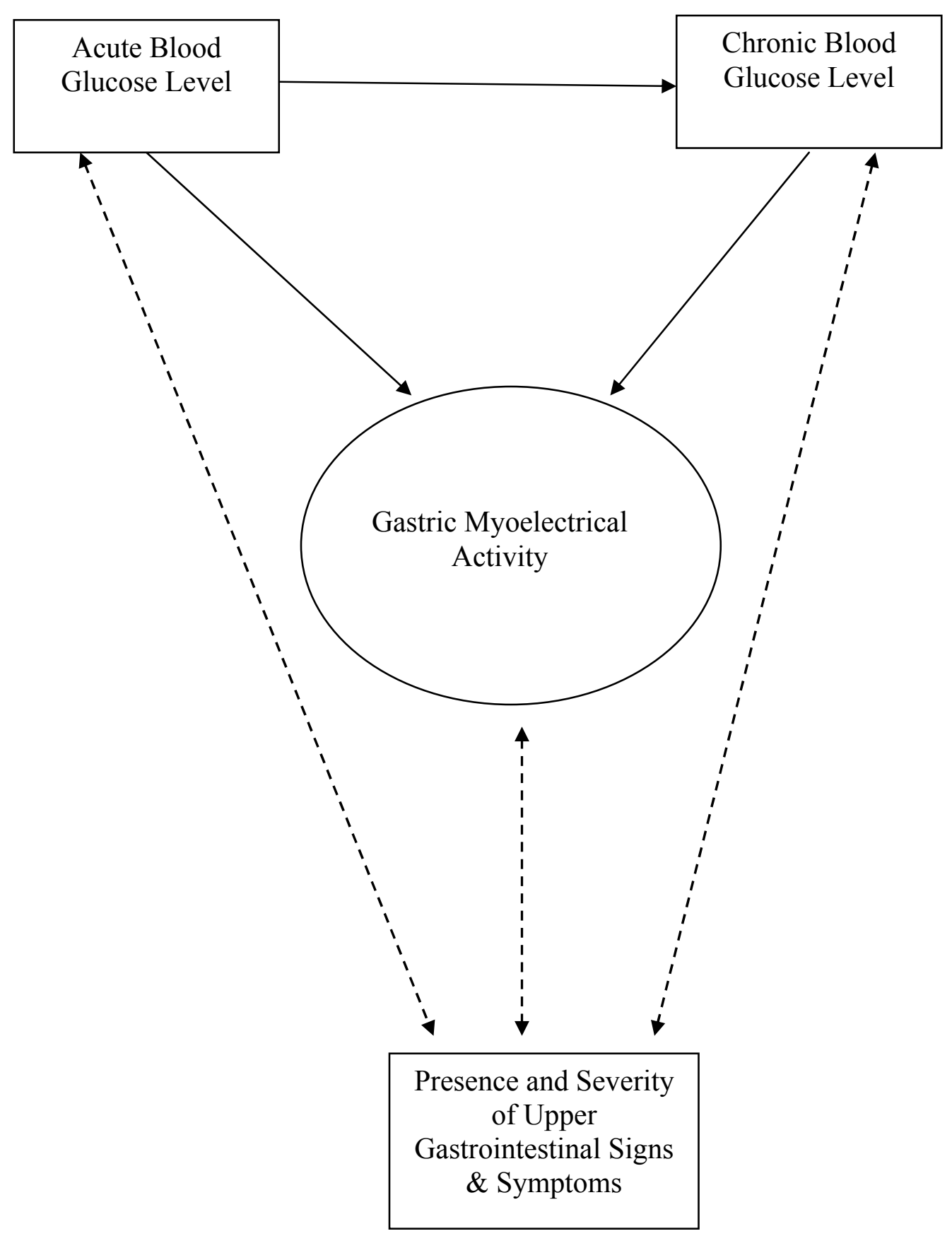

Figure 1. Relationships among Gastric Myoelectrical Patterns, Acute and Chronic Blood Glucose Levels, and Upper Gastrointestinal Signs and Symptoms in Patients with Diabetes Mellitus

Note.

$\longrightarrow \quad$ Factors contributing to diabetes complications.

- $\rightarrow \quad$ Indicates uncertain strength of relationship. 
satiety, or bloating, usually occur (Enck \& Frieling, 1997; Horowitz \& Fraser, 1994; 1995; Horowitz, Wishart, Jones, \& Hebbard, 1996; Koch, 1999; Kong, Macdonald, \& Tattersall, 1996; Rothstein, 1999). Up to $76 \%$ of patients with diabetes in some reports, complain of these upper GI symptoms (Enck \& Frieling, 1997; Horowitz \& Fraser, 1995; Horowitz, Wishart, Jones, \& Hebbard, 1996; Kong, Macdonald, \& Tattersall, 1996), which appear to be associated with acute changes in blood glucose levels (hypo- and hyperglycemia), and altered patterns of GMA (Enck \& Frieling, 1997; Kong, Macdonald, \& Tattersall, 1996; Rothstein, 1999). Studies report that subjects with acute hyperglycemia experience more tachygastria, while subjects with chronically elevated blood glucose levels were more likely to be bradygastric (Mathur, et al., 2001; Jebbink, et al., 1994). Subjects with abnormal EGGs experienced greater GI signs and symptoms in some studies, but other studies report no relationship between GMA and GI signs and symptoms (Soykan, Lin, Sarosiek, \& McCallum, 1999; Pfaffenbach, et al., 1995). Additional factors contribute to digestive problems in patients with diabetes, including length of diagnosis, age, gender, meal composition, and other conditions or diseases. The longer a person has diabetes, the more likely complications will exist (Davidson, 1998; Krall \& Beaser, 1989). Poor metabolic control and the effects of diabetes throughout the body inhibit the ability to compensate for changes occurring due to altered glucose metabolism. Micro- and macrovascular changes affect each organ system. Progressive loss of beta cell function, or lack of insulin sensitivity, reduces the body's ability to accommodate acute blood glucose changes. Nervous system degeneration is inevitable in persons' with long-term loss or lack of glucose control (American Diabetes Association [ADA], 2003; Joslin, 2001; National Institute of 
Diabetes \& Digestive \& Kidney Diseases [NIDDK], 2003). The age at onset of diabetes is important. Younger individuals may experience greater complications in later life. During puberty, persons with type 1 diabetes experience abnormalities in the growth hormone/insulin-like growth factor-1 (GH/IGF-1) axis that leads to a reduction in insulin sensitivity (Acerini, Williams, \& Dunger, 2001). Susceptibility to develop complications is greater during the pubescent growth spurt. Altered GH/IGF-1 levels have been implicated in the long-term complications associated with diabetes (Holly, Amiel, Sandhu, Rees, \& Wass, 1988). These abnormalities are linked to deterioration in glucose control, especially in females.

Diabetes affects gender nearly equally. Of the 20.6 million Americans aged 20 years or older with diabetes, 10.9 million are men, and 9.7 million are women (NIDDK, 2003). The rates of complications for patients with diabetes do vary by gender (Jones, Russo, Stevens, Wishart, Berry, \& Horowitz, 2001). Women typically seek medical attention more frequently than men, and they experience more GI symptoms and depression (Schvarcz, Palmer, Ingberg, Aman, \& Berne, 1996; Soykan, Sivri, Sarosiek, Kiernan, \& McCallum, 1998).

The process of digestion relies on the systematic processing of nutrients and drugs. The GI system's activity is coordinated based upon the composition or type of the meal consumed, along with its volume. High fat or fiber meals require more time to complete the digestive process (Levanon, Zhang, Orr, \& Chen, 1998; NIDDK, 2003). Regulation and feedback mechanisms work together to ensure that digestion occurs at the appropriate rate and fashion to extract useful products from the substance ingested and to excrete those products that are not needed. When these mechanisms do not work as they 
should, GI symptoms exist, the person cannot properly process nutrients and drugs, and there is a mismatch in glucose-insulin utilization. This leads to more frequent hypo and/or hyperglycemic events in patients with diabetes and poor long-term metabolic control.

Comorbid conditions contribute to digestive problems including the presence of neurological disease or injury (e.g. Parkinson's disease, spinal cord injury), eating disorders (e.g. anorexia, bulimia), smooth muscle disorders (amyloidosis, scleroderma), intestinal pseudo-obstruction, or post-surgical problems also affects gastric activity (Aspenall \& Taylor-Robinson, 2002; NIDDK, 2003; Ogawa et al., 2004). Any damage to the nerves that assist in the coordination of gastric activity could alter function. These factors must be taken into account when assessing the presence and severity of GMA abnormalities and GI symptoms in patients with diabetes.

\section{Definition of Concepts}

A lack of standardization exists within the literature for some of the concepts of interest for this study. Therefore, it is necessary to provide a theoretical and operational definition for each concept of the framework in order to establish a point of reference.

Gastric Function. The actions of the GI tract required to initiate and maintain the process of digestion (Thomas, 1997). It is directed by autonomic nervous system activity and chemical and hormonal feedback in the stomach for the purpose of receiving, mixing, and emptying nutrients into the small intestines for absorption, and finally into the large intestine for processing and removal of waste materials. This complex pattern of activity is initiated by the thought, smell, sight, or ingestion of nutrient materials. 
Electrogastrography (EGG). A noninvasive test used to evaluate gastric myoelectrical activity. Electrogastrography measures reflect the slow wave or baseline activity as well as changes in contractility that occurs within a period (Mintchev, 2000; Pfaffenbach, Adamek, Kuhn, \& Wegener, 1995; Smout, Van Der Shee, \& Grashus, 1980). The normal EGG frequency has been reported between 2 to 4 cycles per minute (cpm), with a normal post-prandial increase in amplitude of $1 \mathrm{mV}$ (Bellahsene, Schimer, Updike, \& McCallum, 1992; Familoni, Bowes, Kingma, \& Cote, 1991; Mintchev, 2000; Pfaffenbach, Adamek, Kuhn, \& Wegener, 1995).

Patterns of Gastric Myoelectrical Activity (GMA)._The speed and rhythm of myoelectrical discharges emitted from neurons in the stomach and reflected as frequency waveforms on a tracing. In this study, patterns of GMA will be categorized as normal (frequencies between $2.7-3.2 \mathrm{cpm}$ ), bradygastric (frequencies less than or equal to 2.69 $\mathrm{cpm}$ ), tachygastric (frequencies greater than or equal to $3.21 \mathrm{cpm}$ ), or mixed dysrhythmic (a combination of bradygastria and tachygastria). These characterizations provide insight into the basic electrical rhythm of the stomach, as well as the strength and direction of the contractions that are present (Familoni, 1994; Mintchev, 2000).

Upper Gastrointestinal (GI) Symptoms. Subjective or objective indicators of some alteration in the normal digestive pattern experienced by an individual (Thomas, 1997). Upper GI symptoms were assessed in this study globally using the Total Symptom Score (TSS) and individually using visual analog scales (VAS).

The TSS is a 6-item questionnaire used to evaluate the presence and severity of upper gastrointestinal symptoms and their overall impact on the patient's general health. Individual scores for each symptom on the TSS range from zero to 10, with higher scores 
indicating greater symptom presence and severity. An overall summary score (Sum TSS) was also reported for the previous 2-month period.

A 100mm VAS was used to assess the presence and severity of nausea, vomiting, pain, bloating, and early satiety experienced during the EGG testing procedure. A score of zero indicates no nausea, vomiting, pain, bloating, or early satiety, and a score of 100 indicates the presence of severe symptoms. A detailed description of each symptom measured during this study follows.

Nausea. An unpleasant sensation usually felt when nerve endings in the stomach, or other areas, are irritated. It usually precedes vomiting and may be due to the site or odor of obnoxious matter or materials or mental images of the same (O'Toole, 1997; Thomas, 1997).

Vomiting. A reflexive phenomenon, which culminates with the forceful expulsion of gastric and/or intestinal contents through the mouth. Vomiting frequently occurs with nausea; however, it can occur with or without nausea (O'Toole, 1997; Thomas, 1997).

Pain. A sensation or feeling of distress, discomfort, or suffering caused by stimulation or irritation of sensory nerves (O’Toole, 1997; Thomas, 1997). The present study assessed pain presence/severity specifically over or in the abdomen.

Anorexia. The loss or lack of appetite (O’Toole, 1997; Thomas, 1997).

Satiety. Being full to satisfaction, especially with food (Thomas, 1997).

Bloating. A condition in which the abdomen feels full and tight or distended, usually caused by excessive intestinal gas (Thomas, 1997).

Metabolic Control. The level of long-term blood glucose control. As the hemoglobin in red blood cells travels through the blood stream, it acquires a glucose 
coating or glycosylation. The higher the blood glucose, the more coating the cells acquire. Glycated (glycosolated) hemoglobin (GHB), measures the amount of coating the red cells have acquired over their lifetime, which spans 2 to 3 months. The results of this test will be reported as a glycosolated hemoglobin level percentage (\%). Reference GHB is $4.2 \%$ to $7.0 \%$. The glucose control index for near normal control is $7.0 \%$ to $8.0 \%$; the range indicating good control is $8.0 \%$ to $9.0 \%$; and a GHB level greater than $9.0 \%$ is an indication for action or intervention (Labcorp, 2001). The higher the GHB, the higher the risk that patients will develop complications from diabetes (eye disease, kidney disease, nerve damage, heart disease, and stroke) (Davidson, 1998; Krall \& Beaser, 1989; NIDDK, 2003).

Acute Blood Glucose. Acute measurement of blood glucose levels. Fingerstick blood glucose monitoring (BGM) will be performed to assess acute changes in the circulating glucose during the EGG testing procedure. Information about immediate changes occurring in blood glucose levels relative to intake can be measured with this method (LifeScan, 2002). While acute changes in blood glucose levels may not affect the index for metabolic control (because of averaging of lows and highs over a 2-3 month period), these changes do affect GMA and the perception of symptoms during the episode (Barnett \& Owyana, 1988; Jebbink et al., 1994). Recommended glycemic goals are 80$120 \mathrm{mg} / \mathrm{dl}$ preprandially and average bedtime glucose of $100-140 \mathrm{mg} / \mathrm{dl}$ (ADA, 2003). Testing will be performed using a LifeScan One Touch Ultra ${ }^{\circledR}$ monitoring device. This method of testing will be used to evaluate changes in the blood glucose levels pre- and post-prandially and provide data for assessing changes in patterns of GMA and upper GI symptoms and their severity as the blood glucose level changes. 


\section{Summary}

The conceptual framework for this study guides the organization of the study. Within the framework, diabetes mellitus is a complex disease with multiple factors contributing to the inability to attain and maintain the level of glucose control necessary to reduce diabetes complications. The framework supports the argument that alterations in acute blood glucose levels contribute to changes in the body that perpetuate the inability to achieve long-term glucose control. Damage to the nervous system because of chronic or acute hyperglycemia contributes to change in the normal pattern of GMA. Changes in the normal pattern of GMA lead to digestive system alterations. Alterations in the digestive process affect acute and long-term blood glucose levels and predispose some patients to upper GI symptoms. The presence of GI symptoms may prohibit the patient from ingesting appropriate nutrients, while the alteration in the entire digestive process prohibits the normal processing of nutrients and drugs required to maintain metabolic control. The identification of factors that directly influence the ability to gain glucose control and the ability to describe relationships among patterns of GMA, symptom presence and severity, and metabolic control in patients with diabetes could be used to initiate, formulate, or monitor therapeutic interventions.

\section{Significance of the Study}

The significance of this study lies in the contributions to further knowledge of GMA, pathophysiology of gastric function, and its relationship to GI symptoms in patients who are diagnosed with diabetes mellitus. Data obtained from this pilot study 
provides additional validating information about changes in the patterns GMA, upper GI signs and symptoms, and level of glucose control, in patients with diabetes mellitus.

An important issue in nursing and in healthcare in general, is the increasing prevalence of chronic conditions, such as diabetes. Reducing complications and enhancing adaptation for patients with diabetes can promote health and independence in this population. In the case of the patient with diabetes, identifying and understanding the role of patterns of GMA, the relationship to upper GI symptoms, and the maintenance of glucose control, provides information that can be used to help the healthcare provider plan strategies and treatments. Early and periodic testing of GMA using EGG can be instituted as a health promotion and evaluation strategy. Early identification and routine monitoring of changes in GMA in the patients with diabetes can direct treatments that will reduce upper GI symptoms and improve metabolic control, thereby reducing complications of diabetes mellitus.

\section{Assumptions}

The following assumptions were made in this study:

\section{Transcutaneous EGG measures GMA.}

2. Secondary complications of diabetes mellitus, including alterations in the nervous system, occur because of poor metabolic control.

3. An orderly, processional sequence of events, with appropriate inputs and feedback, must be maintained by the GI system in order for gastric function to occur normally. 
4. Upper gastrointestinal symptoms occur as a result of alterations in gastric function.

5. Gastric function is compromised because of altered patterns of GMA.

6. Consistent, systematic processing of nutrients and drugs is required in order to achieve metabolic control.

7. Normal, healthy controls will exhibit normal patterns of GMA, the absence of upper GI symptoms, and normal metabolic control.

8. Clients will respond honestly and accurately to all questions during the testing session.

\section{Limitations}

The following limitations of this study were identified:

1. There are no alternatives to the use of subjective tools to assess the presence and severity of upper GI symptoms. Self-report is the best means for measuring personal experiences with upper GI symptoms, which is a variable of interest in this study. The investigator must accept and believe the individual's response to be honestly and accurately based upon the experience. Participants were encouraged to provide information based upon their individual assessment of the presence and severity of any symptom experienced. The investigator queried the participant and assisted with completing the tools without leading or prompting the individual's response.

2. Historical reporting of symptom presence and severity may not provide an accurate representation of the patient's experience. Establishing a point of 
comparison relative to other events or problems experienced by the individual may be difficult and become distorted over time. The idea that the person also becomes accustomed to certain levels of discomfort, and therefore no longer perceives it as disruptive, must be taken into account. The investigator directed the participant to select a response based upon the recollection of upper GI symptoms occurring during the previous 2-month period only. Comments or additional information provided which may have influenced symptoms were recorded on the subject's data sheet.

3. Electrogastrography only identifies patterns of GMA. Because of the complex nature of the process of digestion, this single measure may not definitively indicate altered gastric function. Additional measures, such as gastric emptying, weight changes, biochemical assessment of nutritional status, assessment of number of occurrence and volume of vomiting, etc., are not addressed in the present study. No diagnoses were made based upon the assessment of EGG data. Frequency measurements were categorized based upon established normative values and reported as such.

4. Many clinical factors may be present that could affect this study, including certain comorbid diseases and conditions. Therefore, inclusion and exclusion criteria have been established to control for some of these variables.

5. Results of this study cannot be generalized to samples of patients with other diseases and conditions whose pathology may affect gastric function by mechanisms other than those related to changes in GMA. 
6. The Total Symptom Score (TSS) has been used in multiple studies by it authors, but standard reliability and validity information have not been established for this tool. 


\section{CHAPTER 2. REVIEW OF LITERATURE}

\section{Introduction}

The pathological and physiological principles involved in the study of diabetes mellitus, gastric function, gastric complications, and gastric myoelectrical activity, are complex. A conceptual framework has been provided to assist in organizing the presentation of theoretical, clinical, and evidence-based literature related to the present study. This chapter will describe specific literature relevant to the following: 1) pathophysiology of diabetes mellitus, 2) principles of gastric function, 3) gastric complications in patients with diabetes and, 4) gastric myoelectrical activity and electrogastrography.

\section{Pathophysiology of Diabetes Mellitus}

Diabetes is a syndrome of disordered metabolism with inappropriate hyperglycemia due to either an absolute deficiency of insulin secretion or a reduction in the biologic effectiveness of insulin (or both; Feingold \& Funk, 2000; Greenspan \& Gardner, 2001). Diabetes is a chronic disease that has no cure. It is the sixth leading cause of death due to disease in the United States and the third leading cause of death in some minority groups (ADA, 2003; Diabetes Research Working Group [DRWG], 1999; NIDDK, 2003). Diabetes is diagnosed using 3 criteria: 1) fasting plasma glucose $\geq 126$ $\mathrm{mg} / \mathrm{dl}$; 2) symptoms of diabetes plus a random plasma glucose $\geq 200 \mathrm{mg} / \mathrm{dl}$; or 3 ) a plasma glucose level $\geq 200 \mathrm{mg} / \mathrm{dl}$ after an oral dose of $75 \mathrm{~g}$ of glucose (glucose tolerance test; Feingold \& Funk, 2000). There are different classifications of diabetes based upon 
the etiology of the disease. The primary classifications include type 1 diabetes and type 2 diabetes.

Type 1 diabetes is caused by autoimmune destruction of insulin-producing beta cells in the Islets of Langerhans of the pancreas (DRWG, 1999). Persons with this form of diabetes must take insulin injections; without exogenous insulin, death is inevitable (DRWG, 1999). Type 1 diabetes accounts for $5 \%$ to $10 \%$ of all diagnosed cases of diabetes (ADA, 2003; NIDDK, 2003; Palmer \& Lenmark, 1997); it usually occurs in childhood or adolescence (Feingold \& Funk, 2000; Krall \& Beaser, 1989; Palmer \& Lenmark, 1997), but can occur at any age (DRWG, 1999). Evidence suggests that viral infections or toxic environmental insult may precipitate type 1 diabetes in a genetically predisposed person while an aggressive immune system destroys pancreatic beta cells in an attempt to overcome the invasive agent (Feingold \& Funk, 2000; Marsharani \& Karam, 2001).

Type 2 diabetes differs from type 1 diabetes in that type 2 diabetes is believed to be caused by resistance to normal insulin action at the cellular level and by a relative reduction of insulin secretion (ADA, 2003). It is also linked to obesity, a factor that further increases insulin resistance (Feingold \& Funk, 2000). Persons with this form of diabetes may take oral agents, which increase sensitivity to glucose or reduce insulin resistance. In some cases, persons with type 2 diabetes must take insulin injections. Type 2 diabetes accounts for $90 \%$ to $95 \%$ of all diagnosed cases of diabetes (ADA, 2003; Feingold \& Funk, 2000; Kahn \& Porte, 1997; NIDDK, 2003). 


\section{Principles of Gastric Function}

The gastrointestinal (GI) system is the system responsible for taking in and processing nutrients and drugs required to sustain life. The entire process relies on the progression of ingested materials at the appropriate rate through the GI system. Ingested materials are propelled throughout the GI system by a series of coordinated contractions. The underlying mechanisms controlling gastric function are directed by a complicated system of neuronal, electrical, and chemical agents. The central nervous system, autonomic nervous system, enteric nervous system, and chemical (hormonal) controls work in conjunction to control the GI system (Camilleri \& Prather, 1998; Falk, 1992; Goyal \& Hirano, 1996; Lingappa, 2000; Redel \& Zwiener, 1998; Wingate \& Phillips, 1998; Wood, 1998). Under the regulation of these systems, a number of processes are managed to ensure that ingested materials are moved through the GI system to complete the process of digestion.

The GI system is composed of several organs and accessory structures. These include the mouth, salivary glands, esophagus, stomach, liver, gall bladder, pancreas, small intestines, large intestines, rectum, and anus. Each organ has a specific purpose or function. The mouth ingests and begins to mechanically break down the foodstuff. Saliva is added as a lubricant. The esophagus acts as a conduit between the mouth and the stomach. In the stomach, acids are added to the composition and mixing occurs to further grind the materials into liquid form. The liver, gall bladder, and pancreas secrete additional chemicals and enzymes to the mixture as it proceeds through the system to promote the digestive process. In the small intestines, the final stages of chemical digestion occur and the nutrient or drug material is absorbed. The large intestine is 
responsible for the reabsorption of water and the preparation of waste products. Left over products and waste materials pass from the large intestine and are stored in the terminal portion of the large intestine and the rectum until they pass out of the body through the anus.

Neuronal control is the first level controlling gastric function (Lingappa, 2000; Wingate \& Phillips, 1998; Wood, 1998). Only the initial entry of the materials into the system (swallowing) and exit (defecation) are consciously controlled. Sensory input from seeing, smelling, or tasting foods invokes the central nervous system (CNS) to begin the processes required for ingesting and digesting what has been consumed. Pressure or a sensation of "fullness" in the rectum signals the need to evacuate this portion of the GI system. The CNS modulates constant motor activity in the GI system, with an increase in function noted in response to various inputs and feedback mechanisms.

Control or awareness of many bodily activities is beyond human perception. The autonomic nervous system (ANS) monitors these functions and regulates activities to maintain homeostasis. The ANS serves as a conduit for carrying information between the brain and the gut (Kellow, et al., 1999; Rees \& Brown, 1998; Wingate \& Phillips, 1998; Wood, 1998). It is divided into the parasympathetic and the sympathetic systems. The vagus and pelvic nerves supply the parasympathetic nervous system (PNS). These nerves receive and relay information directly from the target organs to the brain on muscle movement and GI system content. The sympathetic nervous system (SNS) is supplied by the spinal cord and provides a route for transmission of noxious stimuli from the organs and tissues of the GI system to the brain. 
The GI system has its own center of control. The enteric nervous system (ENS) acts as an independent, integrated system that provides local control of gut functions, as well as interconnections between the gut, brain, and spinal cord (Kellow et al., 1999; Malagelada \& Camilleri, 1998; Rees \& Brown, 1998; Wingate \& Phillips, 1998; Wood, 1998). The circuits of the enteric nervous system are grouped together to form distinct networks: the myenteric and submucosal plexuses, and the prevertebral ganglia. The myenteric plexus spans the length of the GI tract, lying between the longitudinal and circular muscle layers. The network receives intrinsic and extrinsic innervation. It provides motor innervation to the muscle layers and secretory motor innervation to the mucosa, as well as providing innervation to the enteric ganglia of the gall bladder and pancreas and sympathetic ganglia. The submucosal plexus is comprised of overlapping small and large ganglia found between the circular and mucosal layers of the intestines. This plexus plays an important role in controlling electrolyte secretions. The prevertebral ganglia form structures that connect extrinsic nerve fibers between the gut and spinal cord. This relay system allows for the passing of information between the GI system, spinal cord, and the brain. The enteric nervous system provides direct control of gastrointestinal function through its integrative design, while maintaining a modulatory communication pathway with the central nervous system.

Electrical control is the second level responsible for gastric function. Motor or contractile activity modulated by gastric electrical activity is what actually produces the peristaltic movement through the GI tract (Camilleri \& Prather, 1998; Falk, 1992;

Quigley, 1996; Wingate \& Phillips, 1998). Movement of nutrients through the GI tract is controlled by the programmed patterns of the enteric system. Gastrointestinal motor 
function is managed through a set of commands controlling contractile activity and reflexes. A basic electrical rhythm is initiated in the body of the stomach (Kellow et al., 1999; Malagelada \& Camilleri, 1998; Quigley, 1996; Wingate \& Phillips, 1998). This activity propagates toward the pylorus at a rate of three cycles per minute (Familoni, 1994; Mintchev \& Bowes, 1994; Rees \& Brown, 1998). These slow waves form the basis for contractile activity in the stomach. Actual contractions do not occur with each cycle, but are based upon the imposition of an action potential on the plateau of the slow wave. During a fasting state, activity of the stomach is characterized by a pattern of cyclic electromechanical activity known as the migrating motor complex (MMC). This pattern of activity begins in the stomach and passes down the length of the small intestines about every ninety to one hundred twenty minutes. It has four phases. Phase I is characterized by regular slow waves without superimposed action potentials. This phase produces no motor activity. In phase II, slow waves are accompanied by intermittent action potentials resulting in irregular motor activity. During phase III, action potentials occur with each slow wave, producing regular, rhythmic contractions. Phase IV is the short transition period between constant activity and the return to phase I. Upon ingestion of a meal, the stomach immediately shifts into a fed state of motor activity. This state is characterized by irregular contractile activity in the stomach that last for a variable period, depending upon the type and volume of meal taken in (Falk, 1992; Quigley, 1996; Rees \& Brown, 1998; Wingate \& Phillips, 1998).

Chemical or hormonal mechanisms make up the third level of control in gastric function. An excitatory effect on gastric function is controlled using acetylcholine (Ach) as a transmitter. Inhibition of gastric function is accomplished using norepinephrine as a 
transmitter. Hormones such as gastrin, cholecystokinin, secretin, motilin, glucagon, and vasoactive intestinal polypeptide, along with many others, are secreted in response to the type of nutrient consumed in an effort to control the rate of digestion (Camilleri \& Prather, 1998; Rees \& Brown, 1998; Lingappa, 2000; Malagelada \& Camilleri, 1998). Gastric function is increased or is slowed down based upon feedback within the GI system.

Control and coordination of GI function requires multiple pathways. Alterations and abnormalities in GI motor activities are linked to GI dysfunction. The cause of the abnormality may stem from neurological, electrical, or chemical changes in the GI system. The effects of the alteration or abnormality may be manifest as unpleasant signs and symptoms such as nausea, vomiting, anorexia, bloating, constipation, or diarrhea, or may contribute to other problems associated with other disease and conditions affected by the stomach emptying too fast or too slow (Malagelada \& Camilleri, 1998; Redel \& Zwiener, 1998; Wingate \& Phillips, 1998).

\section{Gastric Complications in Patients with Diabetes}

The first description of dyspeptic symptoms associated with diabetes occurred over fifty years ago (Kassander, 1958; Rundles, 1945). Since then, studies have documented various findings related to the pathophysiology, diagnosis, and treatment of gastric dysfunction in patients with diabetes. Digestion and absorption of nutrients and drugs is important in controlling blood glucose levels and thereby preventing complications. Alterations in blood glucose levels affect the nervous system resulting in changes in the digestive system (Fischer, Heidemann, Hengst, Domschke, \& Konturek, 
1998). Changes in the digestive system contribute to problems with maintaining metabolic control, creating a cyclic pattern that contributes to further complications (ElSalhy \& Sitohy, 2001; Enck \& Frieling, 1997; Jebbink et al., 1994).

Changes in the normal digestive pattern occur in $30 \%$ to $50 \%$ of patients with diabetes (Annese et al., 1999; Enck \& Frieling, 1997; Horowitz \& Fraser, 1994, 1995; Horowitz, Wishart, Jones, \& Hebbard, 1996; Koch, 1999; Rothstein, 1999). Alterations in the normal digestive pattern cause a potential mismatch in circulating insulin and nutrient availability, which increases the number of hyper and hypoglycemic events (Berne, 1996; Enck \& Frieling, 1997; Horowitz \& Fraser, 1994; Horowitz et al., 1996; Koch, 1999). Signs and symptoms reflecting alterations in normally coordinated movement of nutrients through the gastrointestinal tract such as nausea, vomiting, abdominal pain, anorexia, early satiety, or bloating usually occur in those patients experiencing alterations in digestion (Annese et al., 1999; Enck \& Frieling, 1997; Horowitz \& Fraser, 1994, 1995; Horowitz et al., 1996; Koch, 1999; Keshavarzian, Iber, \& Vaeth, 1987; Kong, Macdonald, \& Tattersall, 1996; Rothstein, 1999). Gastric stasis or retention is another consequence of an altered digestive pattern that causes problems in patients with diabetes (Annese et al., 1999; Enck \& Frieling, 1997; Horowitz \& Fraser, 1994, 1995; Horowitz et al., 1996; Koch, 1999; Rothstein, 1999). In published reports, $20 \%$ to $76 \%$ of patients with diabetes complain of upper gastrointestinal symptoms (Annese et al., 1999; Berne, 1996; Enck \& Frieling, 1997; Horowitz \& Fraser, 1994, 1995; Horowitz et al, 1996; Koch, 1999; Kong et al., 1996; Keshavarzian et al., 1987; Rothstein, 1999). An actual determination of the incidence and prevalence of gastric symptoms has not been obtained since symptom occurrence may be intermittent (Barkin et al., 1997; Enck \& Frieling, 
1997) and since only symptomatic patents are usually evaluated (Kong et al., 1996). Correlational studies examining the relationship between gastric function and gastric symptoms have yielded inconsistent findings, moreover, not all patients will relate or report clinical symptoms (Barbar, Steffen, Wyllie, \& Goske, 2000; Chen, Lin, Pan, \& McCallum, 1996; Geldof, Van de Shee, Van Blankenstein, \& Grashuis, 1986; Parkman et al., 1997; Pfaffenbach et al., 1998; Pfaffenbach et al., 1995; Rezende-Filho, 1995; Soykan, Lin, Sarosiek, \& McCallum, 1999).

\section{Gastric Myoelectrical Activity and Electrogastrography}

The ability of the stomach to perform its normal propulsive activity is accomplished through GMA (Smout, Van de Shee, \& Grashuis, 1980), which can be disrupted in patients with diabetes (Annese et al., 1999; Horowitz \& Fraser, 1994; Rothstein, 1999). This cyclic motor activity occurs in a propagating fashion, propelling materials through the digestive system (Camilleri \& Prather, 1998; Davenport, 1982; Koch \& Stern, 1996; Phillips \& Wingate, 1998). Gastric myoelectrical activity can be measured non-invasively, using EGG, in either a laboratory setting or as an ambulatory exam (Bellahsene et al., 1987; Camilleri et al., 1998; Familoni, Bowes, Kingma, \& Cote, 1991; Geldof et al., 1986; Koch, 1999; Mintchev, 2000). The cutaneous measurement of myoelectrical activity is accomplished by placing electrodes over the axis of the stomach, which allows for capturing electrical activity of the upper GI tract. The electrical activity of the stomach, much like that of the heart, follows a rhythmic, oscillating pattern. The tracings obtained record the pattern of GMA in both the fasting and post-prandial states, providing information about the gastric electrical control activity baseline frequency 
(slow waves), electrical response activity (spikes) and rhythm (bradygastria, tachygastria, or dysrhythmias) (Bellahsene et al., 1987; Camilleri et al., 1998; Familoni et al., 1991; Koch, 2001; Maughan \& Leiper, 1996; Mintchev, 2000; Smout et al., 1980). Cycles have been determined to range between 2 and 4 cycles per minute (cpm), with the established norm from 2.7 to $3.2 \mathrm{cpm}$ (Bellahsene et al., 1987; Familoni, 1994; Familoni et al., 1991; Koch, 2001; Mintchev, 2000; Pfaffenbach et al., 1995; Rezende-Filho, 1995). No standard testing procedure for EGG has been established. The test usually includes recording in both fasting and fed states for varying time frames. Levanon and Zhang (1998) found that a recording length of less than 30 minutes reduced the reliability and predictability of the results and therefore recommended a recording length of 30-60 minutes in each state. A trained technician and a computer are required to perform and analyze the EGG. The procedure is easy to perform and requires minimal time to acquire data. Electrogastrography can be easily repeated, does not involve expensive radiographic equipment, pain, or discomfort to the patient, making it an efficient clinical choice for assessing gastric motor activity.

Electrogastrography has been used in multiple studies to assess gastric dysrhythmias and their relationship to gastric symptoms in diabetic patients. In the study of patients with type 1 diabetes, Koch, Stern, Stewart, and Vasey (1989) sought to obtain measures of GMA in diabetic patients with severe nausea and vomiting using EGG, and to determine the effect of long-term drug therapy on upper GI symptoms and EGG. The study evaluated six patients with nausea and vomiting. The patients were three men and three women, between the ages 22 to 65 years. Duration of diabetes ranged from seven to 25 years. The participants reported upper GI symptoms from 3 months to 7 years in 
duration, and were symptomatic at the time of the study. Electrogastrography was performed at baseline and after 6 months of prokinetic therapy. Following an 8-hour fast, EGG was recorded for 30 minutes. At baseline, EGG revealed gastric dysrhythmias. Tachygastria was noted in one patient, bradygastria in two patients, and a flatline pattern in three patients. The normal $3 \mathrm{cpm}$ pattern was absent in all study participants. Mean upper GI symptom score was $17.8 \pm 5$ (range $9-27$ ), with nausea, vomiting, distention, or early satiety rated severe by each patient. After 6 months of medication therapy with domperidone, normal $3 \mathrm{cpm}$ frequencies were recorded from each of the six patients. The mean GI symptoms scores decreased significantly $(3.7 \pm 2.9, \mathrm{p}<0.01)$. These findings support the theory that gastric dysrhythmias and gastric symptoms are electrophysiological abnormalities, which can be assessed using EGG and that normalization of dysrhythmias contribute to symptom improvement.

Soykan, Lin, Sarosiek, and McCallum (1999) studied EGG changes in diabetic patients and investigated the correlation between upper GI symptoms, fasting blood glucose, and gastric myoelectrical abnormalities. Fourteen patients with longstanding type 1 diabetes were assessed using 30-minute fasting and 2-hour post-prandial EGG recordings. Symptoms of nausea, vomiting, early satiety, bloating, and pain were rated on a scale from zero to three, with higher scores indicating more severe symptoms. Mean symptom scores were significantly higher in patients with abnormal EGG than patients with normal EGGs $(2.42 \pm 0.13 \mathrm{cpm}$ vs. $2.0 \pm 0.16 \mathrm{cpm}, \mathrm{p}<0.05)$. There was no significant differences in fasting glucose levels in abnormal EGG patients $(288 \pm 86.4$ $\mathrm{mg} / \mathrm{dl})$ compared to normal EGG patients $(304 \pm 57.6 \mathrm{mg} / \mathrm{dl}, \mathrm{p}=0.214)$, with both groups being hyperglycemic. Seven out of fourteen patients (50\%) studied had abnormal 
EGG findings. Two had dysrhythmic preprandial EGGs and all had decreased postprandial EGG power. Two had normal preprandial EGGs but decreased post-prandial EGG power. The authors concluded that EGG could be an important screening tool for evaluating abnormal gastric motility in symptomatic diabetic patients.

In studies aimed at detecting prominence of abnormal EGG frequency, Mayaudon, et al. (1999) studied 54 type 1 diabetic patients (13 male, 41 female; mean age 43 years) and 15 healthy age and sex matched non-diabetic controls. Diabetic patients were asymptomatic. Electrogastrography was recorded for 4 hours before, during, and 4 hours after the ingestion of a standard meal. The authors found that tachygastria (EGG > $4 \mathrm{cpm}$ ) was significantly more common in type 1 diabetic patients than in controls. Patients experienced more tachygastria than controls throughout the recording period $(38 \% \pm 5$ vs. $23 \% \pm 11.8, \mathrm{p}<0.001)$, as well as before $(37 \% \pm 6$ vs. $26.5 \% \pm 8.9, \mathrm{p}<$ $0.001)$, during $(41 \% \pm 7.8$ vs. $23 \% \pm 10.5, \mathrm{p}<0.001)$, and after the meal $(37 \% \pm 6.9$ vs. $29 \% \pm 9.8, \mathrm{p}<0.001)$. The percentage of dominant frequency in the normal range was significantly lower in patients with diabetes than in controls $(49 \% \pm 6$ vs. $63.3 \% \pm 11.1, p$ $<0.001)$. The authors concluded that EGG could be used for the detection of gastric dysrhythmias in asymptomatic diabetic patients.

Mantides et al. (1997) also assessed GMA in asymptomatic patients with type 1 diabetes. A group of 10 type 1 patients ( 6 men, 4 women, mean age $59.9 \pm 6.1$ years) was compared to 9 healthy controls ( 5 men, 4 women, mean age $49.5 \pm 14.8$ years). Electrogastrography with a 2-hour fasting/post-prandial recording, frequency and fed/fast ratio of slow wave power was assessed. The study found gastric myoelectrical abnormalities, with bradygastria being the predominate frequency $(46.8 \pm 16.2 \%$ time $)$. 
Normogastria was present $35.1 \pm 13.2 \%$ of the time and tachygastria was noted $17.2 \pm$ $10.2 \%$ of the time. Additionally, normogastria did not increase significantly after the meal in patients with diabetes as it did in controls. The fed/fasting ratio of the EGG power was $1.13 \pm 0.25$ for bradygastria, $1.67 \pm 0.33$ for normogastria, and $0.78 \pm 0.35$ for tachygastria. Slow wave power decreased post-prandially in diabetic patients with bradygastria $(0.82 \pm 0.23, \mathrm{p}=0.006)$ and normogastria $(0.73 \pm 0.32, \mathrm{p}<0.0001)$, but not with tachygastria where an increase in EGG power was observed $(3.47 \pm 1.55, \mathrm{p}=$ 0.0002). The authors concluded that gastric dysrhythmias exist without upper GI symptoms and that bradygastria and failure to increase slow-wave amplitude postprandially are the predominant forms of abnormal myoelectrical activity in adults with type 1 diabetes.

Kawagishi et al. (1997) studied GMA in 10 type 1 and 47 type 2 patients with diabetes and 10 healthy control subjects using EGG to elucidate the relationship between glucose control, diabetic autonomic neuropathy, and gastrointestinal motility. Cutaneous EGG was recorded for 1 hour fasting and 1 hour post-prandially in all subjects. The participants were questioned regarding GI symptoms using a standard questionnaire and a 3-point rating scale. Autonomic neuropathy was assessed using standard cardiovascular reflex test. Electrogastrography and autonomic function test were repeated in 12 diabetic patients after glycemic control for 4 weeks. Autonomic neuropathy was identified in 33 of the 57 patients. Eight of the patients had borderline autonomic neuropathy, and 16 had normal autonomic nerve function. The two diabetic groups had similar fasting plasma glucose levels and hemoglobin A1c (HbA1c) concentrations. Normogastria was significantly lower in diabetic patients with autonomic neuropathy $(37 \pm 4 \%)$ than in 
control subjects $(66.7 \pm 5.2 \%, \mathrm{p}<0.01)$. The relationship between the percentage of time in normogastria and $\mathrm{HbAlc}$ concentrations was non-significant in diabetic patients $(\mathrm{r}=\mathrm{-}$ $0.206, p=0.123$ ). The dominant frequency instability coefficient (DFIC) was significantly high in diabetic patients with $(42.4 \pm 2.5 \%)$ and without autonomic neuropathy $(40.8 \pm 3.1 \%)$ as compared to control subjects $(26.2 \pm 1.8 \%, \mathrm{p}=0.01)$. The DFIC was correlated significantly with HbAlc concentrations in diabetic patients $(r=$ $0.315, \mathrm{p}=0.017)$. The post-prandial-to-fasting power ratio $(\mathrm{PR})$ was significantly lower in diabetic patients with autonomic neuropathy $(1.2 \pm 0.1)$ compared with control subjects $(3.1 \pm 0.7)$ or with diabetic patients without autonomic neuropathy $(2.1 \pm 0.2, \mathrm{p}$ $=0.01)$. No significant relationship between the PR and HbAlc concentration was found in diabetic patients. Gastrointestinal symptom scores were significantly higher in patients with autonomic neuropathy as compared to those without autonomic neuropathy. Of the 57 diabetic patients, 27 had GI symptoms. These scores did not, however, correlate with any parameter of GMA during the study. After 4 weeks of glycemic control, the DFIC and the percentage of time in normogastria improved significantly when compared with the baseline period ( $p=0.0096 ; p=0.0409$, respectively), but the PR did not change significantly $(\mathrm{p}=0.05)$. The investigators in this study observed a decrease in the PR and percentage of time in normogastria and an increase in the DFIC in patients with autonomic neuropathy in the absence of glycemic control. They concluded that both glucose control and autonomic nerve function are important factors in regulating GMA, and that changes in GMA are partly reversible with glucose control.

Gad-el-Hak and Bakr (2001) investigated patterns of GMA in type 2 diabetic patients detected by EGG. The study included 34 subjects ( 7 male, 27 female, mean age 
$51.5 \pm 3.5$ years). Using a 30 -minute fasting and 30 - minute post-prandial ambulatory recording, EGG abnormalities were found in 13 patients (38.2\%). One subject had tachygastria, 1 had bradygastria, and 7 had mixed dysrhythmias (periods of bradygastria and tachygastria). Four subjects had decreased post-prandial power. The authors concluded that gastric myoelectrical abnormalities occur in a high proportion of type 2 diabetic patients.

Similarly, Mathur, et al., (2001) assessed the rate of gastric dysrhythmias and post-prandial EGG changes in patients with type 2 diabetes. Seventy-one subjects (44 male, 27 female, mean age $62 \pm 11.9$ years) were studied. Analyzing a 1-hour fasting and 2-hour post-prandial EGG recording, $85 \%$ (60/71) of the patients had abnormalities in the fasting state. The amount of time spent in tachygastria and bradygastria during the fasting state was $21 \pm 13.6 \%$ and $26.1 \pm 21.7 \%$, respectively. The amount of time in normal gastric rhythm was $44.7 \pm 20.2 \%$ while fasting. Eighty-three percent (59/71) of the subjects had gastric rhythm abnormalities in the post-prandial period. The percent tachygastria and bradygastria during the post-prandial state was $24.5 \pm 16.3 \%$ and $21.1 \pm$ $19.2 \%$, respectively. The amount of time in normal rhythm post-prandially was $48.5 \pm$ 19.9\%. Sixty-five percent (46/71) of subjects improved their EGG recordings in response to a test meal; 35\% (25/71) did not respond. Fasting bradygastria was associated with responders, while fasting tachygastria was associated with non-responders. There was no correlation between abnormal EGG rhythms and glucose levels or gastric symptoms. The authors concluded that gastric rhythm disturbances were common in patients with type 2 diabetes and that abnormal gastric rhythms may be predictive of delayed gastric emptying. 
A 2002 study by Qi, Luo, and Wang had findings similar to those in previous studies. This study investigated GMA and its relationship in diabetic patients with upper GI symptoms using EGG. The study valuated 32 symptomatic type 2 patients (17 male, 15 female, mean age 51 years) and 22 healthy controls (11 male, 11 female, mean age 50 years). A 30-minute fasting EGG recording followed by a 30-minute post-prandial recording was used. Patients had a lower instance of normal EGG than controls in both the fasting and the fed states ( $38 \%$ vs. $96 \%, \mathrm{p}<0.01,34 \%$ vs. $86 \%, \mathrm{p}<0.01$, respectively). Patients also had a higher incidence of abnormal EGG (tachygastria and bradygastria) than controls in both the fasting and fed states $(63 \%$ vs. $5 \%, p<0.01,66 \%$ vs. $14 \%, \mathrm{p}<0.01$, respectively). The mean post-prandial dominant frequency was lower for patients $(2.61 \pm 0.29, \mathrm{p}<0.05)$ than for controls $(3.76 \pm 0.14, \mathrm{p}<0.05)$, as was the post-prandial/preprandial dominant frequency ratio $(1.01 \pm 0.10, \mathrm{p}<0.05$ for patients versus $1.28 \pm 0.11, \mathrm{p}<0.05$ for controls). Of the 32 diabetic patients with upper GI symptoms, 21 (66\%) had abnormal EGG. The study supported findings from previous studies, which showed that diabetic patients with upper GI symptoms have GMA that can be assessed using EGG. Results of this study further the knowledge of the complexity of the components of GMA and its importance in normal gastric function.

Electrogastrography in this and previous studies continues to be a useful tool in detecting and assessing changes in GMA.

Controversial studies also exist in the study of GMA in patients with diabetes. Some studies have not found EGG to be a useful tool in determining differences between patients with diabetes and normal controls. Pfaffenbach, et al (1995) investigated whether EGG could really predict a gastric motility disorder in type 2 diabetic patients with 
chronic symptoms. Eighteen patients with type 2 diabetes ( 9 male, 9 female, median age 64) and 20 age and gender matched healthy controls (10 male, 10 female, median age 68 years) were studied. Following an overnight fast, EGG values were obtained during a 1hour fasting and 1-hour fed state. The presence of GI symptoms was assessed immediately before the measurements. The authors found no significant differences among any of the EGG variables between the subjects and controls. Both groups showed predominantly normal frequencies. Bradygastria and tachygastria were significantly less common in both the pre-prandial and post-prandial period in subjects and controls $(\mathrm{p}<$ 0.05). There was no significant correlation between EGG and any of the clinical variables studied, including gastric symptoms and blood glucose. This study concluded that EGG was not a reliable tool for assessing gastric motility.

Jebbink, et al. (1994) examined the prevalence of gastric myoelectrical abnormalities and their relationship to upper GI symptoms in patients with type 1 diabetes. The study was performed in 30 patients (19 male, 11 female, mean age $45.5 \pm$ 2.5 years) and 12 healthy sex, age, and weight matched controls ( 7 male, 5 female, mean age $46.3 \pm 3.7$ years). All participants were interviewed prior to beginning the study to determine the presence and severity of symptoms experienced the week before the study. Upper GI symptoms were also assessed before the start of the meal and at the end of the study. A meal symptom score was calculated from these scores. EGG recordings were obtained for 2-hours fasting and 3-hours after a standard meal. The incidence of dysrhythmias, such as tachygastria and bradygastria, was not higher in patients than in controls ( $17 \%$ and $8 \%$, respectively). There were no differences between patients and controls in mean EGG frequencies in either the fasting or post-prandial state $(0.0489 \pm$ 
0.0006 vs. $0.0478 \pm 0.0001 ; 0.0488 \pm 0.0006$ vs. $0.0494 \pm 0.0009$, respectively). No differences were found between other EGG parameters between patients with and without symptoms during the study. The authors concluded that patients with type 1 diabetes studied under euglycemic conditions did not have grossly disturbed gastric myoelectrical activity except when symptomatic during the study.

El-Salhy and Sitohy (2001) studied GMA in patients $(\mathrm{n}=12,9$ women and 3 men; mean age 45 years) with type 1 diabetes and in controls $(n=38,26$ women and 12 men; mean age 37 years). No statistically significant differences were found in dominant frequencies in either the fasting (controls $3 \pm 0.03 \mathrm{cpm}$ vs. patients $2.9 \pm 0.09 \mathrm{cpm}$ ) or the post-prandial state (controls $3 \pm 0.05 \mathrm{cpm}$ vs. patients $3 \pm 0.09 \mathrm{cpm}$ ). While this study was able to assess GMA, no differences could be found between subjects and healthy controls.

\section{Summary}

In this review, specific literature related to the pathophysiology of diabetes mellitus, gastric complications in patients with diabetes, and GMA in patients with diabetes has been presented. Evidence of similarities and differences between type 1 and type 2 diabetes are emphasized. Controversial results are also presented. Given the information available at this time, the use of EGG in patients with diabetes as a clinical tool remains questionable. Further research is needed to definitively support the use of this technology in this and other patient groups. While EGG consistently detected patterns of altered GMA in these studies, any conclusions drawn about the relationships between GMA, GI symptoms, and metabolic control are viewed tentatively as the studies 
were conducted in small numbers of patients under different conditions. Additional work with a larger sample of symptomatic and asymptomatic participants within a consistent setting would assist in drawing more valid conclusions. The present study will contribute to the pool of knowledge related to GMA, GI signs and symptoms, and level of metabolic control in persons diagnosed with diabetes mellitus by further assessing and/or validating the links between these relationships in a single, controlled study. 


\section{CHAPTER 3. METHODOLOGY}

\section{Introduction}

The hallmark manifestation of diabetes mellitus is an uncontrolled blood glucose level. Hyperglycemic effects are linked to the development of diabetes complications, including the development of autonomic nervous system dysfunction (ADA, 2003; Davidson, 1998; DRWG, 1999; Krall \& Beaser, 1989; NIDDK, 2003). Alterations in gastric function occur because of changes in autonomic function and hormonal regulation. These changes are associated with the development of both upper GI symptoms and hyper- and hypoglycemic events (Camilleri \& Prater, 1998; Creyer, 1998; Davenport, 1982; Horowitz, Wishart, Jones, \& Hebbard, 1996; Koch, 1999; Koch \& Stern, 1996; Muggeo, 1998; Phillips \& Wingate, 1998). Upper GI symptoms and difficulty maintaining metabolic control are among the complaints of patients with diabetes mellitus (Annese, et. al., 1999; Berne, 1996; Enck \& Frieling, 1997; Horowitz \& Fraser, 1994, 1995; Horowitz, Wishart, Jones, \& Hebbard, 1996; Koch, 1999; Kong, Macdonald, \& Tattersall, 1996; Rothstein, 1999).

Not all patients experience upper GI symptoms, but for those who do, the presence of nausea, vomiting, abdominal pain, bloating, and early satiety, is usually unpleasant, and often complicates their self-care practices, adherence to treatment, and ultimately, QOL (Siddique, Ricci, Stewart, Sloan, \& Farup, 2002; Talley, et al., 2001). Changes in the normal digestive pattern contribute to problems with maintaining metabolic control, as there is a mismatch in circulating insulin and nutrient availability (Creyer, 1998; Horowitz, Wishart, Jones, \& Hebbard, 1996; Koch, 1999; Muggeo, 1998). 
The GI system maintains the digestive pattern through contractile and propulsive activity that is driven by GMA. This activity is disrupted because of diabetic neuropathy (Camilleri \& Prater, 1998; Koch \& Stern, 1996; Phillips \& Wingate, 1998).

Electrogastrography allows for the cutaneous measurement of GMA (Familoni, Bowes, Kingma, \& Cote, 1991; Mintchev, 2000; Palmieri, Schulze-Delrieu, \& Raab, 1992; Parkman et al., 1997; Pfaffenbach et al., 1998; Rezende-Filho, 1995). Researchers using EGG have demonstrated the ability to distinguish patterns of GMA in healthy subjects from patterns observed in the presence of disease (Geldof et al., 1986; Pfaffenbach et al, 1995). This instrument is easy to use, costs less, and is less time consuming than other tests of gastric function, and is well tolerated by patients. Assessing GMA in patients with diabetes could prove valuable. Identification of specific patterns of GMA that correlate with specific symptoms and/or levels of metabolic control could be used to assess treatment associated improvements in this population once interventions have been developed to address these problems. While patterns of GMA observed in study patients will be categorized as normogastria, bradygastria, and tachygastria using established cut-points documented in the literature, EGG results reported in this study do not reflect a medical diagnosis. Traditionally suspected gastric dysfunction identified through EGG assessment is confirmed using more sensitive and specific tests.

The purposes of this pilot study were to assess and describe GMA in patients with diabetes mellitus using EGG. Additionally, the study sought to determine if specific patterns of GMA correspond with levels of symptom presence and severity, glucose control, age, or length of diagnosis in patients with diabetes. This chapter presents the 
research design, setting and sample, recruitment, instrumentation, and procedures used in this investigation.

\section{Research Design}

A descriptive, correlation design was used to depict the associations among gastric myoelectrical activity, upper GI symptoms, and glucose control, and to determine whether upper GI signs and symptoms, glucose control, age, or length of diagnosis could be correlated with the pattern of GMA identified using EGG. Measurements of GMA, upper GI signs and symptoms, and glucose control were obtained. Demographic information including age, gender, length of diabetes, diet history, and medications taken, were obtained during patient interview as these factors could influence gastric function or upper GI symptoms. The Institutional Review Board (IRB) of the University of Tennessee Health Science Center granted approval for the study (see Appendix A for the IRB approval).

\section{Setting}

Data were collected at the Center for Health Evaluation and Lifestyle Promotion (HELP Center), which is located on the University of Tennessee Health Science Center (UTHSC) campus in Memphis, Tennessee. The HELP Center is located on the fifth floor of the Professional Building. This center serves as a primary care center, research laboratory, and site for various studies. A designated interview and exam room was setup to accommodate this study, including an area for phlebotomy, completion of demographic information, study questionnaires, and EGG testing. 


\section{Sample}

The total non-probability convenience sample consisted of 25 individuals, 5 subjects diagnosed with type 1 diabetes mellitus, 13 subjects diagnosed with type 2 diabetes mellitus, and 7 healthy controls. The sample was comprised of 17 women and 8 men. Nineteen of the participants were African American, 6 were Caucasian. The following inclusion and exclusion criteria were used to select study participants:

1. General Inclusion Criteria for Subjects and Controls

a. Persons 12 years of age or older;

b. Could read, write, and speak English;

c. Agreed to be in the study.

2. Inclusion Criteria for Subjects Included

a. Diagnosis of type 1 or type 2 diabetes mellitus;

b. Fulfilled general inclusion criteria.

3. Exclusion Criteria for Subjects and Controls

a. Persons less than 12 years of age;

b. Have a history of gastrointestinal disease or conditions (peptic ulcer disease (PUD), gastroesophageal reflux disease (GERD), pancreatitis, uremia, Crohn's disease, ulcerative colitis (UC), irritable bowel disease (IBD), lactose intolerance, or eating disorders (Anorexia, Bulimia);

c. Currently being treated with medications known to affect gastrointestinal motility (Reglan, Cisapride, Domperidone, Erythromycin), gastric acid suppressants (Zantac, Tagamet, Prilosec, Pepcid, Axid, Prevacid, Nexium), or antiemetics (Phenergan, Compazine, Inapsine, Benedryl, Zofran, Kytril) who 
are unable or unwilling to be off the medication for at least 72 hours prior to testing;

d. Pregnancy.

Of the 37 persons originally expressing interest in participating in the study, 27 ultimately participated (72.3\% participation rate). Six subjects repeatedly missed scheduled appointments, and four did not wish to undergo blood sampling. Of the 10 potential participants, 6 were female and 4 were male. Four of the women were diagnosed with type 2 diabetes; 5 were Caucasian. Three of the male subjects were type 1 diabetics; two were Caucasian. The mean age of this group was 25.6 years (range $16-$ 32). Data from 2 participants were lost due to compact disc corruption, making them unreadable. One participant was a 15 year old type 1 African-American female; the second was a 75 year old African-American female serving as a control.

\section{Recruitment}

The participants for this study were recruited through university-associated physicians and nurse practitioners, or from flyers strategically posted in well-traveled locations on the UTHSC Campus and University of Tennessee Bowld (UTB) Hospital. Endocrinologist in practice at local offices agreed to allow participant recruitment during

normal clinic hours. These clinics primarily focused on the management of patients with type 1 and type 2 diabetes and hyperlipidemia. After identification of a potential participant, the physician was consulted or the candidate's medical record was reviewed (with permission of the patient) to determine if eligibility requirements were met. Those candidates meeting inclusion/exclusion criteria were asked if they would be interested in 
participating in the research study. Callers indicating an interest in participating as a patient or normal control in the study were provided with an explanation of the purpose and requirements for the study. Respondents indicating a continued interest in participating in the study and meeting the inclusion/exclusion criteria were scheduled to come into the HELP Center. After a review of the person's medical history, written informed consent (see Appendix B) was obtained and the testing procedures completed as described in the study procedure. Data were collected between October 2002 and March 2004.

\section{Instrumentation}

All data were obtained by the principal investigator and entered immediately into a password protected computerized database. The participant's name, current age, gender, race, marital status, occupation, years of education, and employment status was recorded for demographic consideration. Health history information including height, weight, current medications and illnesses, smoking history, years of diabetes, age at diabetes onset, and for females a menstrual history, was obtained. Address, phone number, and social security number were recorded in a separate password protected database file for re-contact purposes (see Appendix C). Anonymity was ensured after completion of the paper form by replacing the participant's name with a unique identification number generated and cross-referenced by the database entry. The data were backed up to a readonly CD-ROM after each data entry session occurred. Backup discs were secured in a locked file only accessible by the principal investigator and collaborating investigators. 


\section{Procedures}

All participants underwent the same procedure (see Appendix D). Following an overnight fast, the subject was directed to report to the HELP Center. Other directions included taking all regular medications as prescribed (except GI meds excluded previously), and wearing comfortable clothing that would allow for exposure of the

abdomen. At the scheduled appointment time in the HELP Center, informed consent was obtained and a review of medical history was undertaken. Demographic data and blood samples were taken in a designated intake room. In the event the subject was found to be hyperglycemic, treatment according to the plan established by the regular physician or practitioner was implemented. This included administering sliding scale insulin by injection or pump bolus. The participant was encouraged to use the restroom, then directed to a room designated for collection of EGG data.

\section{Measurement of Metabolic Control}

Blood samples were obtained to determine the current level of metabolic control, and to establish a baseline by which one could identify acute changes in blood glucose levels. Approximately 10 milliliters (2 teaspoonfuls) of blood were drawn via peripheral venipuncture by an experienced laboratory technician for the measurement of glycosolated hemoglobin (GHB). Glycosolated hemoglobin measures the overall blood glucose control for the past 2 to 3 months (Labcorp, 2001). As the hemoglobin in red blood cells travels through the blood stream, it acquires a glucose coating or glycosylation. The higher the blood glucose, the more coating the cells acquire. The result of this test was reported as a GHB level (\%). Reference GHB based upon 
laboratory protocol is $4.2 \%$ to $7.0 \%$. The glucose control index for near normal control is $7.0 \%$ to $8.0 \%$; the range indicating good control is $8.0 \%$ to $9.0 \%$; and a GHB level greater than $9.0 \%$ is indication for action or intervention (Labcorp, 2001).

The blood sampling occurred after reviewing and completing the informed consent, demographic form, and symptom questionnaires and prior to beginning EGG data collection. A non-latex tourniquet was applied above the antecubital area of the patient's preferred arm. After identifying an appropriate vessel for venipuncture, the site was prepped with alcohol and allowed to dry. A 22 gauge butterfly catheter with preattached tubing was used to puncture the vein and deliver the sample to a lavender vacutainer tube. The tube was labeled with the individual's unique identifier; the appropriate lab requisition was then completed and the specimen taken within 30 minutes to the laboratory pick-up station.

Fingerstick blood glucose testing was performed to assess acute changes in the circulating glucose in the blood during the EGG testing procedure. This method of testing was used to evaluate changes in the blood glucose levels post-prandially and provide data for assessing changes in patterns of GMA and symptoms as the blood glucose level changed. Recommended glycemic goals are $80-120 \mathrm{mg} / \mathrm{dl}$ preprandially and average bedtime glucose of 100-140 mg/dl (ADA, 2003). Testing was performed using a LifeScan One Touch Ultra ${ }^{\circledR}$ monitoring device prior to beginning EGG data collection, immediately before serving the test meal, and at 30 -minute intervals after eating the meal until the end of the testing procedure. The investigator calibrated the device according to company procedure before each participant session. 
To obtain the sample the participant was allowed to select the finger used to puncture. The finger was cleaned with alcohol and allowed to dry. Pressure was applied to the finger to "milk" blood into its tip. A lancet device was then used to puncture the fingertip. The first drop of blood was wiped away using a clean cotton ball. The next drop was applied to the testing strip. The monitor required 5 seconds to process the specimen; the results were displayed on the meter. The result was recorded on the patient's data collection sheet at that time.

\section{Measurement of Upper Gastrointestinal Symptoms}

The presence and severity of acute upper GI signs and symptoms was assessed prior to beginning collection of EGG data, immediately before, and at 30 minute intervals after the test meal was consumed, until the end of the testing period, using a visual analog scale (VAS) (0-100 mm) to assess each symptom (see Appendix E). Visual analog scale reliability and validity has been tested and found to be a methodologically sound instrument for assessment of subjective phenomenon (Gallagher, Bijur, Latimer, \& Silver, 2002; Gift, 1989; Luria, 1975).

The participant was instructed to draw a single line horizontally across the vertical VAS line at the level relative to his or her symptom. A mark at the level of zero was used to indicate no nausea, vomiting, pain, bloating, or satiety. A mark at the level of 100 used to indicate the presence of severe symptoms. The $100 \mathrm{~mm}$ ruler used to initially draw the line for the VAS was placed next to the line and the mark made by the participant was numerically qualified. The number was recorded on the data collection sheet. An account of past GI symptoms (i.e. historical symptoms) was assessed using the Total Symptom 
Score (TSS) (see Appendix F). The TSS, a 6-item questionnaire, was administered prior to the EGG to evaluate the presence and severity of GI symptoms and their overall impact on the patient's general health over the past 2 months. This instrument has been found a reliable tool to detect the presence and severity of GI symptoms in multiple studies (Abell, Cutts, Cooper \& 1993; Cutts, Abell, Karas, \& Kuns, 1996; Hathaway et al., 1993).

The participant was given the tool and instructions on how to complete it including answering the question related to the individual symptom "yes" or "no". For an affirmative answer the participant was asked to circle the number corresponding to the intensity of the individual symptom over the past two months. The sixth question on the survey was a summary question for which the participant quantified the effects of the combined gastrointestinal symptoms on overall health.

\section{Measurement of Gastric Myoelectrical Activity}

Electrogastrography was used to evaluate GMA. After obtaining consent, collecting initial data and addressing the need to use the bathroom, the participant was taken to the room where the EGG was performed. This room was sound, climate, and light controlled to maximize relaxation. The subject was allowed to rest in a supine position in a reclining chair. The skin on the surface of the abdomen was cleaned with sterile rubbing alcohol and hair shaved, if necessary, to assure adequate electrode contact with the skin. Silver chloride electrodes placed on the abdomen were used to record the EGG using the standard placement arrangement used at the HELP Center (see Figure 2). 


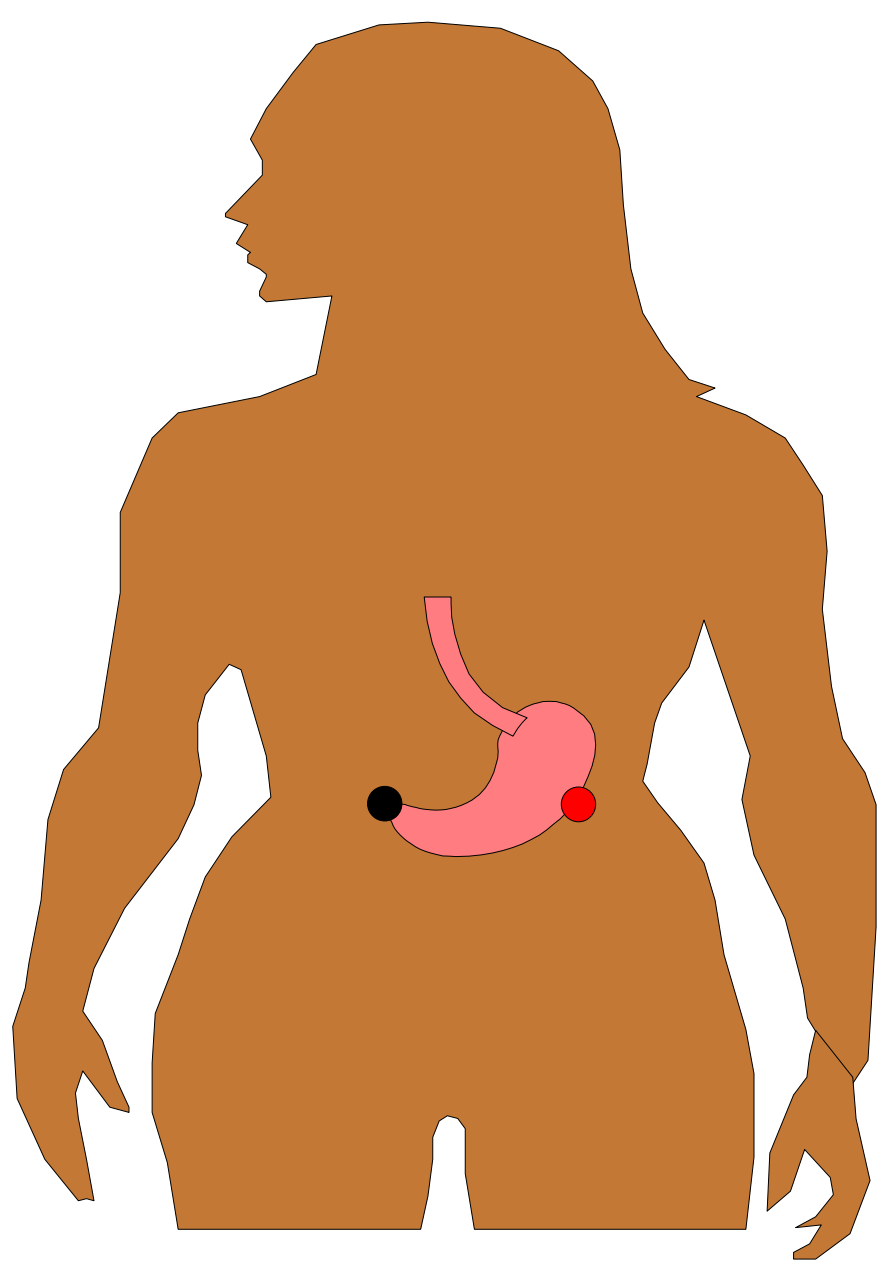

Figure 2. EEG Electrode Placement

Note. EGG electrodes are attached to abdominal wall with a standard positive electrode over the antrum of the stomach on the mid-clavicular line just below the rib cage, a standard negative electrode is placed in a mirror image position on the right side of the abdomen at the mid-clavicular line. 
After 30 minutes of data collection in the fasting state, the participant was served a standard meal consisting of 1 egg, 1 slice of whole wheat bread, and 8 ounces of skim milk (219 kcal, 35\% protein, $52 \%$ carbohydrates, $13 \%$ fat, and 2 gm fiber). Data collection continued for another 1.5 hours to capture activity in the post-prandial or "fed" state. Data from the fasting period, 30 minutes after the meal (first post-prandial period), and 120 minutes after the meal (fifth post-prandial period), were analyzed for the purposes of the present study. These time periods were selected based on previous recommendations and according to their frequency found in the literature. These time periods also allowed consistent with the time normally required for digestion to occur.

Data were collected and analysis was performed on a dedicated personal computer using a Biopac MP-100 system and Acknowledge ${ }^{\text {TM }}$ Software Version 3.71 (Biopac, 2000). The MP 100 system is equipped with 16 analog channels with a input/output voltage range of $\pm 10 \mathrm{~V}$. It has a sampling rate of $70 \mathrm{~K}$ samples/second. The EGG data were transferred to the personal computer via Ethernet interface.

Electrogastrography frequency was determined for each patient by filtering at low/high band pass filter of .016 to $0.25 \mathrm{~Hz}$. This was used to remove any signal below 1 cpm or above $15 \mathrm{cpm}$. A visual inspection of the tracing was completed. Segments noted to have artifacts were deleted. Fast Fourier Transformation (FFT) was completed using the Acknowledge ${ }^{\mathrm{TM}}$ software to obtain the dominant frequency, which translates into the number of cpms of the EGG signal. Example tracings are shown in Figure 3. 


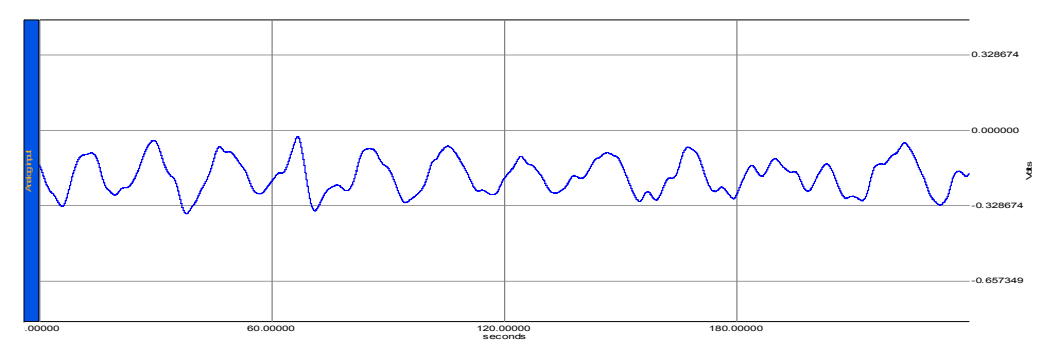

Normogastria

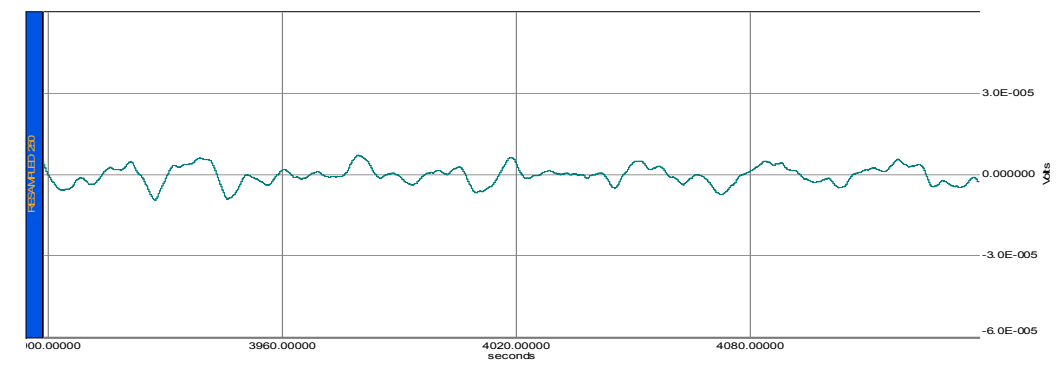

Bradygastria

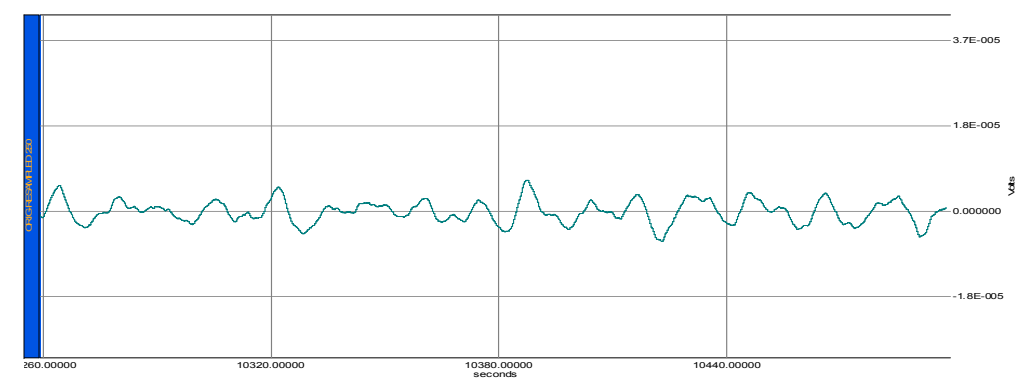

Tachygastria

Figure 3. Examples of EGG Tracings

Note. Sixty-second increments of tracings were visually and electronically reviewed to determine EGG frequency. The vertical bars indicate 60 -second intervals. 


\section{Data Analysis}

The primary investigator gathered all study data, making sure that all questionnaire items were addressed and answers properly recorded during each testing session. Data from questionnaires were coded for confidentiality and anonymity, then transferred to a Microsoft Excel spread sheet and stored on write-protected media. Electrogastrography data files were saved to computer disc at the time of collection. Patient characteristics such as gender, race, age, and other variables were summarized. Descriptive statistics were performed to characterize the sample. The statistical analysis for this study included Chi Square and Kruskal-Wallis testing procedures using SAS 9.1.3. The level of significance was set at .05 for the research questions. Because of the small size obtained during this pilot study, more aggressive data analysis was not appropriate. Small groups were not excluded from the analysis as this would further reduce the sample size.

Specific aims of this study were to 1) characterize the pattern of GMA in patients with diabetes, and 2) describe the relationships among patterns of GMA, symptom presence and severity, acute blood glucose level, long-term metabolic control, age, and length of diagnosis in patients with diabetes. The following two research questions and their associated questions were studied.

\section{Research Question 1}

The following were the questions associated with Question 1 (What patterns of GMA can be assessed using EGG in patients with diabetes?): 
1a. What are the differences in patterns of GMA in healthy individuals versus diabetic patients?

1b. What are the differences in patterns of GMA in patients with type 1 versus type 2 diabetes?

To answer questions $1 \mathrm{a}$ and $1 \mathrm{~b}$, the mean frequency for EGG was determined and patterns of GMA for each period were obtained for the study participants. The values were categorized into bradygastria, tachygastria, or normogastria. Chi square test were utilized to evaluate the differences in frequencies between the normal and diseased groups and between groups diagnosed with type 1 and type 2 diabetes.

\section{Research Question 2}

The following were the questions associated with Question 2 (What is the relationship of patterns of GMA with upper GI symptoms, acute blood glucose measurement, metabolic control, age, and length of diagnosis in patients with diabetes mellitus?):

2a. What is the relationship of patterns of GMA with upper GI symptoms, acute blood glucose measurement, metabolic control, age, and length of diagnosis in patients with diabetes mellitus who are fasting?

2 b. What is the relationship of patterns of GMA with upper GI symptoms, acute blood glucose measurement, metabolic control, age, and length of diagnosis in patients with diabetes mellitus who are 30 minutes post-prandial? 
2c. What is the relationship of patterns of GMA with upper GI symptoms, acute blood glucose measurement, metabolic control, age, and length of diagnosis in patients with diabetes mellitus who are 120 minutes post-prandial?

For research questions $2 \mathrm{a}, 2 \mathrm{~b}$, and $2 \mathrm{c}$, the Kruskal-Wallis test was used to determine if significant relationships existed between variables. The patterns of GMA (bradygastria, normogastria, or tachygastria) were evaluated in relation to the participant's recollection of the presence and severity of UGI signs and symptoms assessed using the TSS, the presence and severity of UGI signs and symptoms during the testing procedure using a VAS, acute blood glucose measurement, GHB, patient age at time of study, and length of diagnosis.

\section{Protection of Human Subjects}

Minimal risks to participants in this study were identified and steps throughout the study to eliminate or reduce risk, maintain participant confidentiality, and assure privacy were included. Risks to the participant during this study included hypo- or hyperglycemia in response to fasting or meal consumption, an increase in gastric symptoms, and pain or hematoma from having multiple blood samples taken. The investigator performed blood glucose monitoring throughout the test, reported the results to the participant, and allowed treatment interventions based upon the participant's usual protocol. Alternate site testing (forearm, hand) was available for those participants wishing to avoid fingersticks, although none chose to use them. These alternative sites have been validated by the monitor manufacturer and in previous studies (Coble, 2001; LifeScan, 2002). An 
assessment of allergies and examination of the participant's skin for signs of irritation was performed prior to securing EGG electrodes. Areas of skin irritation were avoided.

All identifying information was deleted or encrypted to avoid violating any of the participant's legal or ethical rights. The need for the study was fully explained and the participant was given the opportunity to ask questions and received answers to their satisfaction prior to being asked to participate in the study. Assurance that the decision to participate or decline to participate in the study would not affect the care that was normally required or delivered was given. Informed, voluntary written consent was obtained prior to any data collection and a copy of the consent form provided to each subject. The Institutional Review Board (IRB) of UTHSC granted approval for the study. 


\section{CHAPTER 4. RESULTS}

\section{Introduction}

The purposes of this pilot study were to assess and describe GMA in patients with diabetes using EGG, and determine if specific patterns of GMA corresponded with levels of symptom presence and severity, level of glucose control, age, or length of diagnosis during three periods: fasting, 30-minutes post prandial, and 120-minutes post-prandial. Identifying and understanding these relationships could assist the healthcare provider in planning strategies and treatments that reduce the burden and complications of diabetes. This chapter includes a description of the sample demographics, analysis of research questions, and related findings.

\section{Description of the Sample}

All participants meeting inclusion criteria were enrolled. Table 1 summarizes the sample's characteristics. A total of 25 persons participated, including 17 women $(68 \%)$ and 8 men (32\%). The participants ranged in age from 15 to 74 years, with a mean age of $45.5(\mathrm{SD}=14.1)$ years. Nineteen $(76 \%)$ of the participants were African American, six (24\%) were Caucasian. The mean fasting blood glucose measurement for the sample was $165 \mathrm{mg} / \mathrm{dl}$. Fasting blood glucose levels ranged from $71 \mathrm{mg} / \mathrm{dl}$ to $379 \mathrm{mg} / \mathrm{dl}(\mathrm{SD}=$ $83 \mathrm{mg} / \mathrm{dl})$. The mean GHB was 8.24\% (range $=4.9-13.3 \%$; mode 5.7\%). Upper GI symptoms were mildly problematic for the sample with a mean total symptom summary score of $3.48(\mathrm{SD}=2.74)$. The mean fasting EGG frequency for the sample was $2.53 \mathrm{cpm}$ 
Table 1. Descriptive Statistics for Study Participants by Controls and Patients with Type 1 and Type 2 Diabetes

\begin{tabular}{lccc}
\hline & Controls & Type 1 & Type 2 \\
\hline Number of participants & 7 & 5 & 13 \\
Age (years; mean \pm SD) & $37 \pm 13$ & $47.4 \pm 14$ & $49.5 \pm 13.4$ \\
Gender (\%F) & $86 \%$ & $80 \%$ & $54 \%$ \\
Race (\%AA) & $86 \%$ & $60 \%$ & $77 \%$ \\
Fasting Blood Glucose (mg/dl, range) & $104(72-135)$ & $276(196-379)$ & $155(71-277)$ \\
Glycated Hemoglobin (\%, range) & $5.9(4.9-7.7)$ & $10.6(9-12)$ & $8.6(5.9-13.3)$ \\
Total Symptom Score Sum (mean \pm SD) & $2 \pm 1.4$ & $4.6 \pm 2.9$ & $3.8 \pm 3$ \\
Length of Diabetes (years; mean \pm SD) & N/A & $33.4 \pm 10.6$ & $7.9 \pm 4.2$ \\
Age at Onset (years; mean \pm SD) & N/A & $14 \pm 6.4$ & $40.8 \pm 11.8$ \\
Fasting EGG Frequency (cpm; mean \pm SD) & $2.57 \pm .53$ & $2.32 \pm .74$ & $2.60 \pm .47$ \\
\hline
\end{tabular}

Note. $\mathrm{F}=$ Female; $\mathrm{AA}=$ African American; $\mathrm{cpm}=$ cycles per minute. 
$(\mathrm{SD}=.53)$. This indicated that the sample experienced a bradygastric pattern of GMA at the time of the study.

Seven healthy controls $(28 \%)$ were enrolled in this study for comparison with the 18 diabetic patients who participated. This group included 6 females (86\%) and 1 male $(14 \%)$. They ranged in age from 15 to 55 years with a mean age of 37 years $(\mathrm{SD}=13)$. Six of the seven (86\%) controls were African American. The mean fasting blood glucose level was $104 \mathrm{mg} / \mathrm{dl}$. The level ranged from $72 \mathrm{mg} / \mathrm{dl}$ to $135 \mathrm{mg} / \mathrm{dl}(\mathrm{SD}=21 \mathrm{mg} / \mathrm{dl})$. The mean GHB was 5.9\% (range $=4.9-7.7 \%)$. Overall, upper GI symptoms were not problematic for the control group. The mean TSS sum score was $2(\mathrm{SD}=1.4)$. The control group had a mean fasting EGG frequency of $2.57 \mathrm{cpm}(\mathrm{SD}=.53)$, also indicating that this group had bradygastric pattern of GMA.

Five (20\%) of the participants were type 1 diabetics. There were 4 female $(80 \%)$, and 1 male (20\%) in this group. They ranged in age from 30 to 70 years, with a mean age of 47 years $(\mathrm{SD}=14)$. Three of the five $(60 \%)$ were African Americans. The mean fasting blood glucose level for the group was $276 \mathrm{mg} / \mathrm{dl}$. The level ranged from 196 $\mathrm{mg} / \mathrm{dl}$ to $379 \mathrm{mg} / \mathrm{dl}(\mathrm{SD}=72 \mathrm{mg} / \mathrm{dl}$ ). The mean GHB was $10.6 \%$ (range $9-12 \%)$. Upper GI symptoms were moderate in this group with a mean TSS of $4.6(\mathrm{SD}=2.9)$. Years of diabetes for the type 1 group ranged from 24 to 51 years with a mean of 33.4 years ( $\mathrm{SD}=$ 10.6). Age at diagnosis ranged from 5 to 20 with a mean of 14 years $(\mathrm{SD}=6)$. The type 1 diabetic subjects had a mean fasting EGG frequency of $2.37 \mathrm{cpm}(\mathrm{SD}=.74)$. This group had the lowest mean score, which also reflected a bradygastric pattern of GMA.

Thirteen participants (52\%) were type 2 diabetics. There were seven females (54\%) and 6 males (46\%) in this group. They ranged in age from 23 to 74 years, with a 
mean age of 49.5 years $(\mathrm{SD}=13.4)$. Ten of the thirteen $(77 \%)$ were African Americans. The mean fasting blood glucose level was $155 \mathrm{mg} / \mathrm{dl}$. This level ranged from $71 \mathrm{mg} / \mathrm{dl}$ to $277 \mathrm{mg} / \mathrm{dl}(\mathrm{SD}=65 \mathrm{mg} / \mathrm{dl})$. The mean GHB was $8.6 \%($ range $=5.9 \%$ to $13.3 \%)$. Years of diabetes for the type 2 group ranged from 0.83 to 15 years with a mean of 7.9 years (SD $=4.2$ ). Age at diagnosis for this group ranged from 21 to 70 with a mean 40.8 years (SD $=11.8$ ). Overall, upper GI symptoms were reported as mild in this group with a mean TSS of $3.8(\mathrm{SD}=3)$. The type 2 diabetic patients had a mean fasting EGG frequency of $2.60 \mathrm{cpm}(\mathrm{SD}=.47)$. This group had a slightly better mean score than the other groups, but still exhibited a bradygastric pattern.

\section{Statistical Analysis of Results}

\section{Research Question 1}

To answer Question 1 (What patterns of GMA can be assessed using EGG in patients with diabetes?) and 1a (What are the differences in patterns of GMA in healthy individuals versus diabetic patients?), patterns of GMA were categorized as bradygastria, normogastria, or tachygastria, based on previously reported methods. Subjects were grouped based upon whether they were diagnosed with diabetes or not, creating 2 groups: controls or diabetic subjects. At the end of the fasting period, 3 healthy subjects and 10 diabetic patients exhibited bradygastria; 3 healthy subjects and 7 diabetic patients were normogastric; two subjects, 1 healthy subject and 1 diabetic, exhibited tachygastria. At the end of the 30 minute post-prandial period, 2 healthy subjects and 7 diabetic patients were bradygastric. Of the 8 patients with normogastria, 4 were healthy and 4 were 
diabetic. One healthy subject and seven diabetic patients had tachygastria at the end of the 30 minute post-prandial period. At the end of the 120 minutes post-prandial period, 2 healthy subjects were bradygastric and 7 diabetic patients were bradygastric; 2 healthy subjects and 6 diabetic patients were normogastric; 3 healthy subjects and 5 diabetic patients were tachygastric. No significant difference in the pattern of GMA in healthy individuals versus diabetic patients were identified during fasting $(\mathrm{p}=.72)$, at 30 -minutes post-prandial $(\mathrm{p}=.22)$, or 120 -minutes post-prandial $(\mathrm{p}=.76)$. Using Fisher's Exact test, non-significant $p$ values were confirmed during the fasting $(p=.14)$ and 120 -minutes post-prandial periods $(\mathrm{p}=.11)$. A significant $\mathrm{p}$ value was noted at 30 -minutes postprandial $(\mathrm{p}=.04)$. This suggests that no difference exist between patterns of GMA in healthy subjects and patients with diabetes except during the period immediately after eating. Table 2 summarizes these findings.

To answer question $1 \mathrm{~b}$ (What are the differences in patterns of GMA in patients with type 1 versus type 2 diabetes?), patterns of GMA were again categorized as bradygastria, normogastria, or tachygastria. Diabetic subjects were classified by disease type (1 or 2). At the end of the fasting period, 3 patients with type 1 diabetes and 7 patients with type 2 diabetes had bradygastria. Two type 1 diabetics and 5 type 2 diabetics had normogastria. There were no patients with type 1 diabetes with tachygastria at the end of the fasting period, but there was 1 patient with type 2 diabetes identified. Three patients with type 1 diabetes and 4 with type 2 diabetes were found to have bradygastria at the end of the 30 minute post-prandial period. One type 1 diabetic patient and 3 type 2 diabetic patients were normogastric. One patient with type 1 diabetes, and 6 
Table 2. Patterns of Gastric Myoelectrical Activity in Healthy Controls versus Diabetic Patients by Testing Period

\begin{tabular}{|c|c|c|c|c|}
\hline \multicolumn{2}{|c|}{ Frequency } & $\begin{array}{c}\text { Controls } \\
n=7\end{array}$ & $\begin{array}{l}\text { Diabetic } \\
n=18\end{array}$ & Fisher's $p$ \\
\hline & $\mathrm{B}$ & 3 & 10 & .14 \\
\hline \multirow[t]{3}{*}{ Fasting } & $\mathrm{N}$ & 3 & 7 & \\
\hline & $\mathrm{T}$ & 1 & 1 & \\
\hline & B & 2 & 7 & $.04 *$ \\
\hline 30-minutes & $\mathrm{N}$ & 4 & 4 & \\
\hline \multirow[t]{2}{*}{ Post-prandial } & $\mathrm{T}$ & 1 & 7 & \\
\hline & $\mathrm{B}$ & 2 & 7 & .11 \\
\hline 120-minutes & $\mathrm{N}$ & 2 & 6 & \\
\hline Post-prandial & $\mathrm{T}$ & 3 & 5 & \\
\hline
\end{tabular}

Note. $\mathrm{B}=$ Bradygastria; $\mathrm{N}=$ Normogastria $; \mathrm{T}=$ Tachygastria. Categories do not reflect diagnosed gastric dysfunction. 
with type 2 diabetes were found to be tachygastric at the end of the 30 minute postprandial period. At the end of the 120 minute post-prandial period, 2 type 1 patients and 5 type 2 patients had bradygastria; 2 type 1 patients and 4 type 2 patients were normogastric; 1 patient with type 1 diabetes and 4 patients with type 2 diabetes were tachygastric. No significant differences in the pattern of GMA were identified in type 1 versus type 2 diabetic patients during any sampling period $(\mathrm{p}=.81, .49$, and .88 , respectively). No significant $p$ values were found when Fisher's Exact test procedure was used $(\mathrm{p}=.29, .11$, and, .18 , respectively). Table 3 summarizes these findings.

\section{Research Question 2}

To answer Question 2 (What is the relationship of patterns of GMA with upper GI symptoms, acute blood glucose measurement, metabolic control, age, and length of diagnosis in patients with diabetes mellitus?) and $2 \mathrm{a}$ (What is the relationship of patterns of GMA with upper GI symptoms, acute blood glucose measurement, metabolic control, age, and length of diagnosis in patients with diabetes mellitus who are fasting?), the Kruskal-Wallis test of group differences was used. Established patterns of GMA (bradygastria, normogastria, or tachygastria) were evaluated in relation to the diabetic participant's recollection of the presence and severity of UGI signs and symptoms assessed using the TSS (i.e. historical symptoms), the presence and severity of UGI signs and symptoms during the testing procedure using a VAS, acute blood glucose measurement, GHB, patient age at time of study, and length of diagnosis during the fasting period. Variable mean scores are summarized in Table 4. At the end of the fasting period (time 1), there were 7 patients with normogastria, 10 with bradygastria, and 1 with 
Table 3. Patterns of Gastric Myoelectrical Activity in Type 1 versus Type 2 Diabetic Patients by Testing Period

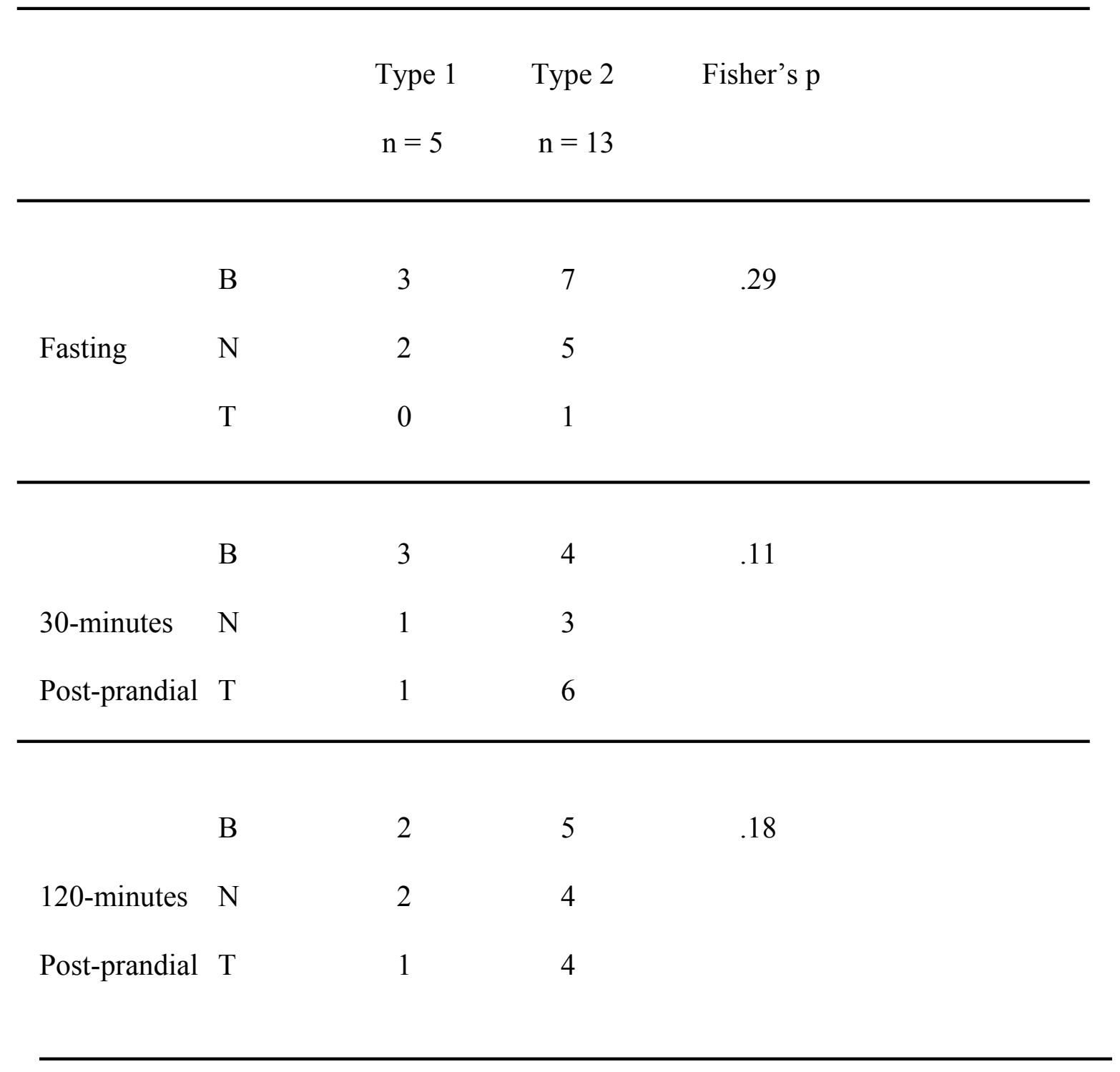

Note. $\mathrm{B}=$ Bradygastria; $\mathrm{N}=$ Normogastria $; \mathrm{T}=$ Tachygastria . 
Table 4. Mean Scores for Patterns of Gastric Myoelectrical Activity and Study Variables in Patients with Diabetes Mellitus Who Were Fasting (Period 1)

\begin{tabular}{|c|c|c|c|c|}
\hline Variable & $\begin{array}{c}\mathrm{N} \\
\mathrm{n}=7 \\
\text { Mean }( \pm \mathrm{SD})\end{array}$ & $\begin{array}{c}\text { B } \\
n=10 \\
\text { Mean }( \pm \mathrm{SD})\end{array}$ & $\begin{array}{c}\mathrm{T} \\
\mathrm{n}=1 \\
\text { Mean }( \pm \mathrm{SD})\end{array}$ & $\mathrm{p}$ \\
\hline FBG & $209.7(98.4)$ & $178.6(82.3)$ & 140 & .88 \\
\hline GHB & $9.6(2.9)$ & $8.8(2.4)$ & 9.3 & .96 \\
\hline Age (years) & $53(17)$ & 47 (10) & 41 & .29 \\
\hline Years DM & $15(9.8)$ & $17(18)$ & 5 & .57 \\
\hline \multicolumn{5}{|l|}{ TSS Results } \\
\hline Nausea & $1.4(2.4)$ & $4.3(3.7)$ & 0 & .15 \\
\hline Bloating & $1.7(2.9)$ & $3.6(4.7)$ & 0 & .52 \\
\hline Anorexia & $.7(1.9)$ & $1.7(2.4)$ & 0 & .47 \\
\hline Pain & $1.6(3.0)$ & $1.5(2.2)$ & 0 & .74 \\
\hline Satiety & 0 & $3.4(3.6)$ & 0 & $.04 *$ \\
\hline Sum & $3.4(2.6)$ & $4.9(3.0)$ & 0 & .23 \\
\hline \multicolumn{5}{|c|}{ VAS Results } \\
\hline Nausea & 9.29 & $4.5(11.2)$ & 0 & .87 \\
\hline Vomiting & 9.50 & 0 & 0 & 1.0 \\
\hline Pain & 8.14 & $5.5(9.8)$ & 0 & .39 \\
\hline Bloating & 8.57 & $16.8(27.7)$ & 0 & .57 \\
\hline Satiety & 9.28 & $6.2(19)$ & 0 & .87 \\
\hline Anorexia & 8.79 & 9.5 (19) & 0 & .66 \\
\hline
\end{tabular}

Note. $\mathrm{B}=$ Bradygastria; $\mathrm{N}=$ Normogastria; $\mathrm{T}=$ Tachygastria. $\mathrm{FBG}=$ Fasting Blood Glucose. GHB = Glycohemoglobin. Sum = Summary Score. TSS = Total Symptom Score (Historical Symptoms). VAS = Visual Analog Scale (Acute Symptoms). $* p<.05$. 
tachygastria. The normogastric group had the highest mean FBG, GHB, age, and length of diagnosis (Years DM). The bradygastric group reported greater mean scores for symptom presence and severity historically and during the fasting period on all upper GI signs and symptoms. The tachygastric subject reported no upper GI signs and symptoms. During this period, satiety on the TSS scale was the only variable yielding any significant result $(\mathrm{p}=.04)$. Patients who were normogastric and those who were tachygastric reported equal mean scores of 6.50 , while those with bradygastria had a mean score of 11.90 , indicating that subjects in the bradygastric group experienced satiety at a higher frequency and severity than subjects in the other groups. For this sample, no relationship was found between the three patterns of GMA and acute blood glucose, metabolic control, age, or length of diagnosis in patients with diabetes who were fasting.

In regard to question $2 b$ (What is the relationship of patterns of GMA with upper GI symptoms, acute blood glucose measurement, metabolic control, age, and length of diagnosis in patients with diabetes mellitus who are 30 minutes post-prandial?), summary statistics are shown in Table 5. The Kruskal-Wallis test was used to answer question $2 \mathrm{~b}$. The number of patients in each category of GMA changed during the first post-prandial period (30 minutes post meal). During this testing period, 4 subjects were normogastric, 7 were bradygastric, and 7 were tachygastric. The tachygastric subjects had the lowest mean score for acute blood glucose, GHB, and length of diagnosis, but had the highest mean score for age at the time of the study. The normogastric subjects reported the lowest mean scores nausea and for the summary score on the TSS. This group reported no other signs and symptoms. The bradygastric group had lower mean scores for nausea, bloating, 
Table 5. Mean Scores for Patterns of Gastric Myoelectrical Activity and Study Variables in Patients with Diabetes Mellitus Who Were 30-Minutes Post Prandial (Period 2)

\begin{tabular}{|c|c|c|c|c|}
\hline Variable & $\begin{array}{c}\mathrm{N} \\
\mathrm{n}=4 \\
\text { Mean }( \pm \mathrm{SD})\end{array}$ & $\begin{array}{c}\text { B } \\
n=7 \\
\text { Mean }( \pm \mathrm{SD})\end{array}$ & $\begin{array}{c}\mathrm{T} \\
\mathrm{n}=7 \\
\operatorname{Mean}( \pm \mathrm{SD})\end{array}$ & $\mathrm{p}^{*}$ \\
\hline BG & $211.8(125.8)$ & $179.4(67.1)$ & $144.7(47.9)$ & .47 \\
\hline GHB & $8.92(3.18)$ & $9.9(1.7)$ & $8.54(2.9)$ & .47 \\
\hline Age (years) & $40(12)$ & 49 (14) & $53(12)$ & .46 \\
\hline Years DM & $12(14)$ & $20(16)$ & $2(10)$ & .48 \\
\hline \multicolumn{5}{|l|}{ TSS Results } \\
\hline Nausea & 0 & $4.7(4.1)$ & $2.1(2.7)$ & .21 \\
\hline Bloating & 0 & $4.0(5.0)$ & $2.9(3.6)$ & .28 \\
\hline Anorexia & 0 & $1.1(2.0)$ & $2.0(2.6)$ & .32 \\
\hline Pain & 0 & $2.0(2.3)$ & $1.7(3.1)$ & .22 \\
\hline Satiety & 0 & $3.1(3.4)$ & $1.7(3.4)$ & .18 \\
\hline Sum & $1.75(1.7)$ & $5.1(3.0)$ & $4.3(2.9)$ & .17 \\
\hline \multicolumn{5}{|l|}{ VAS Results } \\
\hline Nausea & 0 & $5.0(13.2)$ & $.3(.8)$ & .74 \\
\hline Vomiting & 0 & 0 & 0 & 1.0 \\
\hline Pain & 0 & $7.1(12.9)$ & $.7(1.9)$ & .20 \\
\hline Bloating & 0 & $3.6(9.4)$ & $8.1(20.7)$ & .49 \\
\hline Satiety & 0 & $7(1.9)$ & $8.6(22.7)$ & .74 \\
\hline Anorexia & 0 & $1.4(3.8)$ & $.7(1.9)$ & .74 \\
\hline
\end{tabular}

Note. $\mathrm{B}=$ Bradygastria; $\mathrm{N}=$ Normogastria; $\mathrm{T}=$ Tachygastria $. \mathrm{BG}=$ Blood Glucose. $\mathrm{GHB}$ $=$ Glycohemoglobin. Sum $=$ Summary Score. TSS $=$ Total Symptom Score (Historical Symptoms). VAS = Visual Analog Scale (Acute Symptoms).

$* \mathrm{p}<.05$. 
pain, satiety, and summary scores on the TSS, and lower mean scores for nausea, pain, and anorexia scores on the VAS than the tachygastric group. The tachygastric group had the highest mean scores for anorexia on the TSS, and the highest mean scores for bloating and satiety on the VAS. There were no significant differences found between distributions of scores for the patterns of GMA (Table 5). These results indicate that mean scores representing the presence and severity of historical and acute UGI signs and symptoms, 30-minute post-prandial blood glucose, GHB, age, and length of diagnosis in patients with diabetes, were comparable between the three patterns of GMA.

For question 2c (What is the relationship of patterns of GMA with upper GI symptoms, acute blood glucose measurement, metabolic control, age, and length of diagnosis in patients with diabetes mellitus who are 120 minutes post-prandial?), summary statistics are shown in Table 6. The Kruskal-Wallis test was used. The number of patients in each category of GMA changed during this period. During period 5, 6 subjects were normogastric, 7 were bradygastric, and 5 were tachygastric. The normogastric subjects had the lowest mean score for acute blood glucose. The bradygastric group had the lowest mean score for GHB. The normogastric group had the lowest mean score for age. The bradygastric group had the highest mean score for length of diagnosis. The normogastric subjects reported the lowest mean scores on the TSS for nausea, bloating, and satiety, and the highest mean scores on the VAS for pain and satiety. The bradygastric group had lowest mean score for pain on the TSS and reported no pain on the VAS. The tachygastric group had the lowest mean scores for anorexia and the lowest mean score for the summary score on the TSS, and the highest mean scores for 
Table 6. Mean Scores for Patterns of Gastric Myoelectrical Activity and Study Variables in Patients with Diabetes Mellitus Who Were 120-Minutes Post Prandial (Period 5)

\begin{tabular}{|c|c|c|c|c|}
\hline Variable & $\begin{array}{c}\mathrm{N} \\
\mathrm{n}=6 \\
\text { Mean }( \pm \mathrm{SD})\end{array}$ & $\begin{array}{c}\text { B } \\
n=7 \\
\text { Mean }( \pm \mathrm{SD})\end{array}$ & $\begin{array}{c}\mathrm{T} \\
\mathrm{n}=5 \\
\operatorname{Mean}( \pm \mathrm{SD})\end{array}$ & $\mathrm{p}$ \\
\hline BG5 & $154(43.3)$ & $184(110.9)$ & 177 (54.9) & .69 \\
\hline GHB & $9.5(1.8)$ & 8.24 (1.9) & $10(3.8)$ & .62 \\
\hline Age (years) & 49 (12) & 49 (12) & 49 (18) & .81 \\
\hline Years DM & 19 (19) & $15(10)$ & $10(10)$ & .70 \\
\hline \multicolumn{5}{|l|}{ TSS Results } \\
\hline Nausea & $1.8(2.9)$ & $4.3(4.4)$ & $2.4(2.5)$ & .55 \\
\hline Bloating & $2.3(3.7)$ & $2.9(4.9)$ & $2.8(3.9)$ & .98 \\
\hline Anorexia & $1.3(2.1)$ & $2.0(2.6)$ & 0 & .26 \\
\hline Pain & $2.0(2.3)$ & $.7(1.9)$ & $1.8(3.5)$ & .48 \\
\hline Satiety & $.5(1.2)$ & $3.7(4.0)$ & $1(2.2)$ & .18 \\
\hline Sum & $3.8(2.8)$ & $4.4(2.9)$ & $3.8(3.6)$ & .92 \\
\hline \multicolumn{5}{|c|}{ VAS Results } \\
\hline Nausea & $1.7(2.6)$ & $9.3(20.5)$ & 0 & .40 \\
\hline Vomiting & 0 & 0 & 0 & 1.00 \\
\hline Pain & $3.3(5.2)$ & 0 & 0 & .12 \\
\hline Bloating & 8.7 (17.9) & $7.9(20.7)$ & $4(8.9)$ & .49 \\
\hline Satiety & $11.7(21.6)$ & $10.7(28.3)$ & $20(44.7)$ & .54 \\
\hline Anorexia & $.8(2.0)$ & $13.6(35.9)$ & $16(35.8)$ & .97 \\
\hline
\end{tabular}

Note. $\mathrm{B}=$ Bradygastria; $\mathrm{N}=$ Normogastria; $\mathrm{T}=$ Tachygastria. $\mathrm{BG}=$ Blood Glucose. $\mathrm{GHB}$ $=$ Glycohemoglobin; Sum $=$ Summary Score; TSS $=$ Total Symptom Score (Historical Symptoms); VAS = Visual Analog Scale (Acute Symptoms); * $<.05$. 
satiety and anorexia on the VAS. There were no significant differences found between the distributions of mean scores for the patterns of GMA. These results indicate that the scores representing the presence and severity of historical and acute upper GI signs and symptoms, 120-minute post-prandial blood glucose, GHB, age, and length of diagnosis in patients with diabetes, were comparable between the three patterns of GMA. 


\section{CHAPTER 5. DISCUSSION}

\section{Introduction}

Diabetes mellitus is a complex disease with multiple factors contributing to the inability to attain and maintain the level of glucose control necessary to reduce diabetes complications. Alterations in acute blood glucose levels contribute to changes in the body that perpetuate dysfunction. Long-term metabolic control is an essential component in the reduction of complications of diabetes. Alterations in the digestive process affect acute blood glucose levels and predispose some patients to upper GI signs and symptoms. Upper GI signs and symptoms are linked to altered patterns of GMA. The presence of upper GI signs and symptoms may prohibit the patient from ingesting appropriate nutrients, while the alteration in the entire digestive process prohibits the normal processing of nutrients and drugs required to maintain metabolic control. Damage to the nervous system because of chronic or acute hyperglycemia contributes to change in the normal pattern of GMA. Changes in the normal pattern of GMA lead to digestive system alterations. This vicious cycle of altered digestion and insulin-nutrient mismatch increases complications from diabetes.

The identification of factors that directly influence the ability to gain metabolic control and the ability to describe relationships among patterns of GMA, upper GI sign and symptom presence and severity, and acute and long-term metabolic control in patients with diabetes could be used to formulate, initiate, or monitor therapeutic interventions. Previous studies evaluating GMA in patients with diabetes have yielded key information as well as conflicting results. Assessment of patterns of GMA and their 
relationship to upper GI signs and symptoms, and acute and long-term metabolic control under varying conditions have been performed. Further studies are needed to generate data that can be used to explain the relationship between GMA abnormalities and upper GI signs and symptoms, lack of acute and long-term metabolic control, and increased diabetic complications. The aims of this research study were to assess and describe patterns of GMA in patients with diabetes controlling for multiple variables, and to determine if specific patterns of GMA corresponded with upper GI sign and symptom presence and severity and level of acute and long-term metabolic control in patients with diabetes mellitus. This chapter elaborates on the findings of this study and its limitations and strengths; discusses implications and recommendations for future research; and presents conclusions.

\section{Demographic Findings}

There were 5 patients with type 1 diabetes in the present study. This group ranged in age from 30 to 70 years (mean $47.4 \pm 13.9), 4$ of the $5(80 \%)$ were female. Three of the $5(60 \%)$ were African American. Thirteen patients with type 2 diabetes participated in this study. This group ranged in age from 23 to 74 years (mean $49.5 \pm 13.4$ ). Seven of the 13 subjects were female (54\%). Ten of the 13 (77\%) were African American. Patient demographics were compared with data from previous studies of GMA in patients with diabetes. Eleven previous studies of GMA in patient with diabetes were reviewed. While the total number of participants varied greatly, overall demographic characteristics of study participants in the current study were consistent with other studies. In studies of patients with type 1 diabetes, participant numbers ranged from 6 to 57 subjects. Subjects 
ranged in age from 22 years to 69 years. Of 183 patients with type 1 diabetes participating in these studies, $108(59 \%)$ were female. Studies assessing patients with type 2 diabetes included 18 to 71 patients. These studies, which included a total of 155 subjects, reported mean ages ranging from 51 years to 64 years, and had similar numbers of men $(n=77)$ and women $(n=78)$. Three of the previous studies were conducted in the United States. The other studies were completed internationally at hospitals and research institutes in Japan, France, Greece, Egypt, China, Germany, the Netherlands, and Sweden. Ethnic and racial background information was not presented in the studies reviewed. National Diabetes Statistics in the United States (NIDDK, 2005) report that there is a slight difference in the ratio of male to female incidence of diabetes, with $10.5 \%$ of all men aged 20 years or older having diabetes, while only $8.8 \%$ of all women aged 20 years or older have diabetes. Non-Hispanic blacks are noted to be 1.8 times as

likely to have diabetes as non-Hispanic whites of similar age. The current study included a greater female to male ratio of participants, but this discrepancy may have resulted because of the number of females seeking health care traditionally exceeds the rate reported for men (Bertakis, Azari, Helms, Callahan, \& Robbins, 2000). Participants were primarily recruited from health care settings and were thus seeking health care.

\title{
Study Aims
}

\begin{abstract}
Aim 1
Aim 1 of this study was to characterize the patterns of gastric myoelectrical activity in patients with diabetes. Electrogastrography reflects the GMA of the stomach. This electrical activity, measured cutaneously by electrodes placed over the abdomen,
\end{abstract}


provides objective information about frequency, rhythm, and power of contractions in the stomach. By studying EGG tracings of GMA patterns can be discerned. Recording EGG over time and following the feeding of subjects, allowed the investigator to the opportunity to identify changes in the patterns of GMA in response to a stimulus (feeding). Findings of this study support the potential use of EGG in the detection of patterns of GMA in both healthy and diabetic individuals. The availability of a quick, simple to use, non-invasive tool that captures objective data relative to GMA and causes little burden to the patient, provides the healthcare provider with data on which to base or modify treatment interventions if these patterns reflect associated changes in gastric function and symptoms. Using EGG, bradygastric, normogastric, and tachygastric patterns were identified in both healthy controls and patients diagnosed with diabetes. While the full range of patterns was present in healthy controls, these patterns were not interpreted as dysfunction because the EGG is not an accepted diagnostic tool.

At the end of the initial fasting period in the present study, healthy subjects were either normogastric or bradygastric. Diabetic patients were also more likely to be bradygastric or normogastric. A shift toward normogastria occurred during the 30 minute post-prandial period in healthy subjects, while diabetic subjects became more tachygastric. This difference in the pattern of GMA was the only significant difference found between healthy and diabetic subjects in the current study $(p=.04)$. At the end of the 120 minute post-prandial period, there were more healthy subjects exhibiting tachygastric patterns of GMA, while the proportion of diabetic subjects was nearly equal in the three categories. However, these differences in patterns of GMA were not statistically significant. These results are similar to results in studies conducted by 
Mantides et al. (1997), Mathur et al. (2001), and Qi et al. (2002). These investigators found that bradygastria was significantly more common during the recording period and in particular during the fasting state and the period of meal consumption in diabetic patients than in controls. Additionally, in these studies the presence of normogastria did not increase significantly after the meal in diabetic patients as it did in controls. Also in diabetic patients, the dominant frequency decreased post-prandially at the spectra of bradygastria and normogastria, unlike the controls, who exhibited a post-prandial increase.

\section{$\operatorname{Aim} 2$}

Aim 2 of this study was to describe the relationships among patterns of gastric myoelectrical activity, gastrointestinal symptoms, and glucose control in patients with diabetes. Previous studies have investigated GMA in relation to various factors including, glucose control, autonomic nerve function, dyspeptic symptoms, gastric emptying, and medication therapy. None of the studies, however, combined these variables in the same manner as the current study. Assessing the relationship of GMA with upper GI symptoms, acute blood glucose measurement, metabolic control, age, and length of diagnosis in patients with diabetes who were fasting, 30 minutes post-prandial, and 120 minutes post-prandial, while controlling for comorbid conditions affecting GI function and meal composition, was felt to be essential in order to support the conceptual framework proposed for this study and supported by published research.

No significant relationships were identified between patterns of GMA with upper GI symptoms, acute blood glucose measurement, metabolic control, age, and length of 
diagnosis in diabetic patients who were fasting, 30 - or 120 -minutes post-prandial. This finding is possibly due to the small sample size and adaptation of diabetic participants to chronically elevated blood glucose levels or to the presence of chronic upper GI symptoms. The only significant findings were the difference in patterns of GMA in healthy individuals versus diabetic patients at the second post-prandial period, and the presence and greater severity of satiety on the TSS during the fasting period for the diabetic group.

Differences between patterns of GMA in healthy individuals versus diabetic patients were an expected finding. Persons without diagnosed diabetes, neurological, or other comorbid conditions affecting gastric function, i.e., healthy individuals, were not expected to have abnormal EGG frequencies, while the progression of nervous system dysfunction and altered GMA in persons with long-standing diabetes or lack of glucose control is reported in the literature (ADA, 2003; Joslin, 2001, NIDDK, 2003). One healthy subject was found to have tachygastria during the fasting and 30-minute postprandial periods. This healthy individual also had elevated acute blood glucose measurements, an elevated GHB, and reported more acute and historical GI symptoms. This individual was likely an undiagnosed diabetic. Follow up with a primary care physician was encouraged and a referral made.

A change in the EGG frequency would also be consistent with the normal response to the stomach shifting from a "fasting" to a "fed" state (Rees \& Brown, 1998; Wingate \& Phillips, 1998). This shift was apparent in both controls and diabetic subjects, which suggests that EGG results in this study were sensitive to this change. However, the PI was not blinded during interpretation of EGG tracings therefore there is the risk that 
interpretation of study results might be biased by the knowledge of what the data reflected—fed versus fasting tracings. No significant differences were identified between individuals with type 1 versus type 2 diabetes. This finding is consistent with the results of studies conducted by Kawagishi et al. (1997).

Diabetic patients with bradygastria reported more satiety than patients who were normogastric or tachygastric during fasting. This finding is particularly noteworthy because it suggests that the EGG for diabetic patients in this study seemed to be appropriately sensitive to a symptom that in theory would occur in the presence of bradygastria. Theoretically a decrease in GMA is associated with a concomitant decrease in contractile activity. This decrease in the contractile activity is responsible for peristaltic movement of materials through the GI tract leading to gastric stasis, which would cause the patient to feel "full" or satiated (Malagelada \& Camilleri, 1998; Redel \& Zwiener, 1998; Wingate \& Phillips, 1998). Previous studies are inconsistent in reports of upper GI symptoms in patients with diabetes, especially in relation to EGG patterns and level of glucose control (Jebbink, et al., 1994; Koch, et al., 1989; Mathur, et al., 2001; Qi, et al., 2002; Soykan, et al., 1999).

\section{Limitations and Strengths}

There were several methodological limitations to this study. First, the small sample size decreased the power of the study and probably diminished the investigator's ability to determine some statistical associations. This increased the likelihood of making a type II error. Secondly, the ability to analyze all aspects of the EGG tracings was limited by the equipment and software applications available to the investigator. The 
development of newer EGG technology continues to make the capture and analysis of GMA a more valid and reliable measure. Thirdly, concurrent measurement of other factors associated with gastrointestinal function, such as radionucleotide gastric emptying, analysis of chemical and hormonal mediators affecting motility, or autonomic function test were not performed in this study. Completing these additional tests could have helped to discover how these factors contribute or affect gastric function, glucose control, and upper GI symptoms. Inclusion of these tests would also determine if the observed patterns of GMA were associated with the expected changes in gastric function.

Despite these methodological limitations, this study makes an important contribution. Assessments of GMA using EGG in relation to acute and chronic blood glucose measures and upper GI symptoms over time are lacking, and further exploration is needed to assist in clarifying the relationship between these variables.

\section{Clinical Relevance}

The findings of this study, though tentative, could have an important impact on clinical practice. Patients with long-standing, poorly controlled diabetes are likely to experience difficulty with gastric function and report upper GI symptoms. None of the participants in this study had a definitive diagnosis of gastroparesis or disordered gastric motility. Some had undergone endoscopy or gastric emptying studies to detect the possible etiology for the current GI distress, but no relationship between this distress, GI motility, and problems with glucose management was communicated with the patient by their health care provider. Assessing patterns of GMA in relation to upper GI symptoms, glucose control, and other variables could provide additional information to help the 
clinician treat the cause of the complaints, particularly if other more sensitive tests indicated associated changes in gastric function.

Electrogastrography is an attractive alternative for assessing gastric problems and the etiology behind ineffective blood glucose control. The use of EGG in the clinical setting can provide a quick, non-invasive, inexpensive, highly tolerable test to screen and monitor abnormal gastric motility if patterns of GMA are associated with changes in gastric function. The ability to objectively determine patients who experience motility disturbances, and identify the type of gastric rhythm and any corresponding symptoms, could assist the care provider in planning and monitoring appropriate treatments.

\section{Theoretical Implications}

The study findings provided partial support for the conceptual model depicting relationships among acute blood glucose level, chronic blood glucose level, the presence and severity of upper GI signs and symptoms and patterns of GMA identified using electrogastrography. No direct interactions were found between GMA and levels of blood glucose control in the study. Patients with bradygastria and tachygastria had higher, but not significantly different scores for upper GI symptoms during the study, except for satiety in patients who were fasting. There was no association between chronic blood glucose levels and upper GI symptoms. Thus, further testing of the conceptual model in a larger sample should be undertaken because results may reflect a type II error. Future studies should also address previously identified limitations such as the use of more sophisticated EGG technology and measures of gastric function. 


\section{Conclusions}

Research in the area of GMA in patients with diabetes is still relatively new. Many aspects of this research require further investigations under controlled conditions to determine actual significance of the information obtained. Gastric myoelectrical activity has been identified as one of the variables controlling gastric motility.

Electrogastrography has continued to develop as a tool for assessing GMA. A significant relationship between motility and GI symptoms has been identified in some studies, but not others. Diabetic patients in this study who were asymptomatic were found to have abnormal patterns of GMA. Healthy subjects with abnormal GMA and upper GI symptoms were also identified. Findings of this study support the use of EGG as a potential screening tool in the detection of patterns of GMA in healthy and diabetic individuals. The clinical utility of EGG would be confirmed if future studies document a clear association between gastric patterns obtained with EGG and alterations in gastric function obtained with invasive measures. The availability of a quick, simple to use, noninvasive tool that captures objective data relative to GMA and causes little burden to the patient, provides the healthcare provider with data on which to base or modify treatment interventions. Using EGG, gastric myoelectrical activity can be identified in both healthy controls and patients diagnosed with diabetes. Further studies are needed to generate data that can be used to explain the pathology behind, and relationship between, GMA abnormalities, upper GI signs and symptoms, and the lack of glucose control in patient with diabetes. 


\section{LIST OF REFERENCES}

Abell, T. L., Cutts, T. F., \& Cooper, T. (1993). Effect of cisapride therapy for severe dyspepsia on gastrointestinal symptoms and quality of life. Scand J Gastroenterol Suppl, 195, 60-63; discussion 63-64.

Acerini, C. L., Williams, R. M., \& Dunger, D. B. (2001). Metabolic impact of puberty on the course of type 1 diabetes. Diabetes Metab, 27(4 Pt 2), S19-25.

Alvarez W. C. (1922).The electrogastrogram and what it shows. JAMA, 78(15):1116-18.

Annese, V., Bassotti, G., Caruso, N., De Cosmo, S., Gabbrielli, A., Modoni, S., et al. (1999). Gastrointestinal motor dysfunction, symptoms, and neuropathy in noninsulindependent (type 2) diabetes mellitus. J Clin Gastroenterol, 29(2), 171-177.

American Diabetes Association. (2003). Diabetes facts and figures. Retrieved June 20, 2006 from http://www.diabetes.org/about-diabetes.jsp.

American Diabetes Association. (2000). Implications of the diabetes control and complications trial. Diabetes Care, 23(Suppl 1), S24-S26.

Barbar, M., Steffen, R., Wyllie, R., \& Goske, M. (2000). Electrogastrography versus gastric emptying scintigraphy in children with symptoms suggestive of gastric motility disorders. J Pediatr Gastroenterol Nutr, 30(2), 193-197.

Barkin, J., Robbins, E., \& Stein, B. (1997). Diabetes and the GI system. In Porter, D. \& Sherwin, R. (eds). Diabetes mellitus ( $5^{\text {th }}$ ed). Stamford, CT: Appleton \& Lange.

Barnett, J. L., \& Owyang, C. (1988). Serum glucose concentration as a modulator of interdigestive gastric motility. Gastroenterology, 94(3), 739-744.

Bellahsene, B., Schimer, B., Updike, O., \& McCallum, R. (1992). Validation of the transcutaneous electrogastrogram (EGG) using intraoperative implanted electrodes in humans. Gastroenterology, 92, 1313.

Berne, C. (1996). Hypoglycaemia and gastric emptying. Diabet Med, $13(9$ Suppl 5), S2830 .

Bertakis, K. D., Azari, R., Helms, L. J., Callahan, E. J., \& Robbins, J. A. (2000). Gender differences in the utilization of health care services. J Fam Pract, 49(2), 147-152.

Biopac. (2000). Biopac Data Acquisition and Analysis Systems, Inc. research catalog. Santa Barbara, CA: Biopac Systems. 
Camilleri, M., Hasler, W. L., Parkman, H. P., Quigley, E. M., \& Soffer, E. (1998). Measurement of gastrointestinal motility in the GI laboratory. Gastroenterology, 115(3), 747-762.

Camilleri, M., \& Prather, C. (1998). Gastric motor physiology and motor disorders. In M. Feldman, B. Scharschmidt \& M. Sleisenger (Eds.), Sleisenger \& Fordtran's gastrointestinal an liver disease: pathophysiology/diagnosis/management (6th ed). Philadelphia, PA: WB Saunders.

Chen, J. D., Lin, Z., Pan, J., \& McCallum, R. W. (1996). Abnormal gastric myoelectrical activity and delayed gastric emptying in patients with symptoms suggestive of gastroparesis. Dig Dis Sci, 41(8), 1538-1545.

Coble, J. Y. (2001). Comparative evaluation of alternative-site capillary, blood glucose systems for accuracy, precision, perceived ease of use, and pain in patients with diabetes. Unpublished Dissertation, University of Tennessee, Health Science Center. Memphis, TN.

Cryer, P. (1998). Managing diabetes: lessons from type1 diabetes mellitus. Diabet Med, 15(Suppl 4), S8-S12.

Cucchiara, S., Franzese, A., Salvia, G., Alfonsi, L., Iula, V. D., Montisci, A., et al. (1998). Gastric emptying delay and gastric electrical derangement in IDDM. Diabetes Care, 21(3), 438-443.

Cutts, T. F., Abell, T. L., Karas, J. G., \& Kuns, J. (1996). Symptom improvement from prokinetic therapy corresponds to improved quality of life in patients with severe dyspepsia. Dig Dis Sci, 41(7), 1369-1378.

Davenport, H. (1982). Physiology of the digestive tract (5th ed.). Chicago, IL: Year Book Medical Publishers.

Davidson, M. (1998). Diabetes mellitus: diagnosis and treatment (4th ed.). Philadelphia, PA: WB Saunders.

Diabetes Control and Complications Trial Research Group. (1993). The effects of intensive treatment of diabetes on the progression of long-term complications in insulindependent diabetes mellitus. $N$ Engl J Med, 329, 977-986.

Diabetes Research Working Group (DRWG). (1999). Conquering diabetes: a strategic plan for the $21^{\text {st }}$ century. Retrieved May 24, 2003 from http://www.niddk.nih.gov/federal/ dwg/dwgmain.htm\#1.

El-Salhy, M., \& Sitohy, B. (2001). Abnormal gastrointestinal endocrine cells in patients with diabetes type 1: relationship to gastric emptying and myoelectrical activity. Scand $J$ Gastroenterol, 36(11), 1162-1169. 
Enck, P., \& Frieling, T. (1997). Pathophysiology of diabetic gastroparesis. Diabetes, 46 (Suppl 2), S77-81.

Falk, G. W. (1992). Antroduodenal manometry. Dig Dis Sci, 37(12), 1927.

Familoni, B. O. (1994). Validity of the cutaneous electrogastrogram. In J. D. Chen \& R. McCallum (Eds.), Electrogastrography: principles \& applications. New York, NY: Raven Press.

Familoni, B. O., Bowes, K. L., Kingma, Y. J., \& Cote, K. R. (1991). Can transcutaneous recordings detect gastric electrical abnormalities? Gut, 32(2), 141-146.

Funk, J. L., Feingold, K. R. (2000). Disorders of the endocrine pancreas. In S. J. McPhee, Pathophysiology of disease: an introduction to clinical medicine. Norwalk, CT: Appleton \& Lange.

Fischer, H., Heidemann, T., Hengst, K., Domschke, W., \& Konturek, J. W. (1998).

Disturbed gastric motility and pancreatic hormone release in diabetes mellitus. $J$ Physiol Pharmacol, 49(4), 529-541.

Gad-el-Hak, N., \& Bakr, A. M. (2001). Gastric myoelectrical activity in diabetics with and without diabetic autonomic neuropathy. Hepatogastroenterology, 48(38), 590-593.

Gallagher, E. J., Bijur, P. E., Latimer, C., \& Silver, W. (2002). Reliability and validity of a visual analog scale for acute abdominal pain in the ED. Am J Emerg Med, 20(4), 287290.

Geldof, H., van der Schee, E. J., van Blankenstein, M., \& Grashuis, J. L. (1986).

Electrogastrographic study of gastric myoelectrical activity in patients with unexplained nausea and vomiting. Gut, 27(7), 799-808.

Gift, A. G. (1989). Visual analogue scales: measurement of subjective phenomena. Nurs Res, 38(5), 286-288.

Goyal, R. K., \& Hirano, I. (1996). The enteric nervous system. N Engl J Med, 334(17), 1106-1115.

Greenspan, F. S., \& Gardner, D. G. (2001). Basic and clinical endocrinology (6th ed). New York, NY: Lange Medical Books.

Hathaway, D., Abell, T., Cardoso, S., Hartwig, M., Elmer, D., Horton, J., et al. (1993). Improvement in autonomic function following pancreas-kidney versus kidney-alone transplantation. Transplant Proc, 25(1 Pt 2), 1306-1308. 
Holly, J. M., Amiel, S. A., Sandhu, R. R., Rees, L. H., \& Wass, J. A. (1988). The role of growth hormone in diabetes mellitus. J Endocrinol, 118(3), 353-364.

Horowitz, M., \& Fraser, R. (1994). Disordered gastric motor function in diabetes mellitus. Diabetologia, 37(6), 543-551.

Horowitz, M., \& Fraser, R. J. (1995). Gastroparesis: diagnosis and management. Scand J Gastroenterol Suppl, 213, 7-16.

Horowitz, M., Wishart, J. M., Jones, K. L., \& Hebbard, G. S. (1996). Gastric emptying in diabetes: an overview. Diabet Med, 13(9 Suppl 5), S16-22.

Jebbink, R. J., Samsom, M., Bruijs, P. P., Bravenboer, B., Akkermans, L. M., VanbergeHenegouwen, G. P., et al. (1994). Hyperglycemia induces abnormalities of gastric myoelectrical activity in patients with type I diabetes mellitus. Gastroenterology, 107(5), 1390-1397.

Jones, K. L., Russo, A., Stevens, J. E., Wishart, J. M., Berry, M. K., \& Horowitz, M. (2001). Predictors of delayed gastric emptying in diabetes. Diabetes Care, 24(7), 12641269.

Joslin Diabetes Clinic. (2001). Avoiding the long-term complications of diabetes. Retrieved May 24, 2003 from http://www.joslin.org/managing_your_diabetes_3294.asp.

Kahn, S. \&, Porte, D. (1997). Ellenberg \& Rifkin's diabetes mellitus. 5th ed. Stamford, CT: Appleton \& Lange.

Kassander, P. (1958). Asymptomatic gastric retention in diabetics (gastroparesis diabeticorum). Ann Intern Med, 48(4), 797-812.

Kawagishi, T., Nishizawa, Y., Emoto, M., Maekawa, K., Okuno, Y., Taniwaki, H., et al. (1997). Gastric myoelectrical activity in patients with diabetes. Role of glucose control and autonomic nerve function. Diabetes Care, 20(5), 848-854.

Kellow, J. E., Delvaux, M., Azpiroz, F., Camilleri, M., Quigley, E. M., \& Thompson, D. G. (1999). Principles of applied neurogastroenterology: physiology/motility-sensation. Gut, 45(Suppl 2), II17-24.

Keshavarzian, A., Iber, F. L., \& Vaeth, J. (1987). Gastric emptying in patients with insulin-requiring diabetes mellitus. Am J Gastroenterol, 82(1), 29-35.

Koch, K. L. (1999). Diabetic gastropathy: gastric neuromuscular dysfunction in diabetes mellitus: a review of symptoms, pathophysiology, and treatment. Dig Dis Sci, 44(6), 1061-1075. 
Koch, K. L., \& Stern, R. M. (1994). Electrogastrographic data acquisition and analysis. In J. D. Chen \& R. McCallum (Eds.), Electrogastrography: principles \& applications. New York, NY: Raven Press.

Koch, K. L., \& Stern, R. M. (1996). Functional disorders of the stomach. Semin Gastrointest Dis, 7(4), 185-195.

Koch, K. L., Stern, R. M., Stewart, W. R., \& Vasey, M. W. (1989). Gastric emptying and gastric myoelectrical activity in patients with diabetic gastroparesis: effect of long-term domperidone treatment. Am J Gastroenterol, 84(9), 1069-1075.

Kong, M. F., Macdonald, I. A., \& Tattersall, R. B. (1996). Gastric emptying in diabetes. Diabet Med, 13(2), 112-119.

Krall, L., \& Beaser, R. (1989). Joslin diabetes manual (12 ed.). Philadelphia, PA: Lea \& Febiger.

Laboratory Corporation of America (LabCorp). (2001). Directory of services and interpretative guide. Kansas City, MO: LabCorp.

Levanon, D., Zhang, M., \& Chen, J. D. (1998). Efficiency and efficacy of the electrogastrogram. Dig Dis Sci, 43(5), 1023-1030.

LifeScan. (2002). One Touch Ultra users manual. Milpitas, CA: LifeScan.

Lin, Z., Eaker, E. Y., Sarosiek, I., \& McCallum, R. W. (1999). Gastric myoelectrical activity and gastric emptying in patients with functional dyspepsia. Am J Gastroenterol, 94(9), 2384-2389.

Lingappa, V. R. (2000). Physiological medicine: a clinical approach to basic medical physiology. New York, NY: McGraw-Hill/Appleton \& Lange.

Luria, R. E. (1975). The validity and reliability of the visual analogue mood scale. $J$ Psychiatr Res, 12(1), 51-57.

Malagelada, J. R., \& Camilleri, M. (1984). Unexplained vomiting: a diagnostic challenge. Ann Intern Med, 101(2), 211-218.

Mantides, A., Stefanides, G., Kioulanis, J., Tzovaras, G., Epanomeritakis, E., \& Xynos, E. (1997). Cutaneous electrogastrography for the assessment of gastric myoelectrical activity in type I diabetes mellitus. Am J Gastroenterol, 92(7), 1190-1193.

Mathur, R., Pimentel, M., Sam, C. L., Chen, J. D., Bonorris, G. G., Barnett, P. S., et al. (2001). Postprandial improvement of gastric dysrhythmias in patients with type II diabetes: identification of responders and nonresponders. Dig Dis Sci, 46(4), 705-712. 
Maughan, R. J., \& Leiper, J. B. (1996). Methods for the assessment of gastric emptying in humans: an overview. Diabet Med, 13(9 Suppl 5), S6-10.

Mayaudon, H., Bauduceau, B., Dupuy, O., Cariou, B., Ceccaldi, B., Farret, O., et al. (1999). Assessment of gastric neuropathy using electrogastrography in asymptomatic diabetic patients. Correlation with cardiac autonomic neuropathy. Diabetes Metab, 25(2), 138-142.

Mintchev, M. P. (2000). Cyberzine on electrogastrography [Electronic Version]. Retrieved May 24, 2000 from http://www.enel.ucalgary.ca/people/Mintchev/www.html.

Mintchev, M. P., Kingma, Y. J., \& Bowes, K. L. (1993). Accuracy of cutaneous recordings of gastric electrical activity. Gastroenterology, 104(5), 1273-1280.

Muggeo, M. (1998). Accelerated complications in Type 2 diabetes mellitus: the need for greater awareness and earlier detection. Diabet Med, 15(Suppl 4), S60-62.

National Institute of Diabetes and Digestive and Kidney Diseases. (1999). Diabetes statistics. Retrieved January 24, 2000 from http://www.niddk.nih.gov/health/diabetes/ pubs/dmstats/dmstats.html.

Ogawa, A., Mizuta, I., Fukunaga, T., Takeuchi, N., Honaga, E., Sugita, Y., et al. (2004). Electrogastrography abnormality in eating disorders. Psychiatry Clin Neurosci, 58(3), 300-310.

O’Toole, M. (1997). Miller-Keene encyclopedia \& dictionary of medicine, nursing, \& allied health $\left(6^{\text {th }}\right.$ ed). Philadelphia, PA: Saunders.

Palmieri, Y., Schulze-Delrieu, K., \& Raab, J. (1992). Test of gastric motility. In S. Anuras (Ed.), Motility disorders of the gastrointestinal tract: principles \& practice. New York, NY: Raven Press.

Parkman, H. P., Hasler, W. L., Barnett, J. L., \& Eaker, E. Y. (2003). Electrogastrography: a document prepared by the gastric section of the American Motility Society Clinical GI Motility Testing Task Force. Neurogastroenterol Motil, 15(2), 89-102.

Parkman, H. P., Miller, M. A., Trate, D., Knight, L. C., Urbain, J. L., Maurer, A. H., et al. (1997). Electrogastrography and gastric emptying scintigraphy are complementary for assessment of dyspepsia. J Clin Gastroenterol, 24(4), 214-219.

Pfaffenbach, B., Adamek, R. J., Kuhn, K., \& Wegener, M. (1995). Electrogastrography in healthy subjects. Evaluation of normal values, influence of age and gender. Dig Dis Sci, 40(7), 1445-1450. 
Pfaffenbach, B., Adamek, R. J., \& Lux, G. (1998). [The value of electrogastrography for the diagnosis of gastroenterologic function]. Dtsch Med Wochenschr, 123(28-29), 855860 .

Pfaffenbach, B., Wegener, M., Adamek, R. J., Schaffstein, J., Lee, Y. H., \& Ricken, D. (1995). Antral myoelectric activity, gastric emptying, and dyspeptic symptoms in diabetics. Scand J Gastroenterol, 30(12), 1166-1171.

Phillips, S., \& Wingate, D. (1998). Functional disorders of the gut. London: Churchill Livingstone.

Qi, H. B., Luo, J. Y., Zhu, Y. L., \& Wang, X. Q. (2002). Gastric myoelectrical activity and gastric emptying in diabetic patients with dyspeptic symptoms. World $J$ Gastroenterol, 8(1), 180-182.

Quigley, E. M. (1996). Gastric and small intestinal motility in health and disease. Gastroenterol Clin North Am, 25(1), 113-145.

Rezende-Filho, J. (1995). [Myoelectric gastric activity using cutaneous electrogastrography-- electrogastrogram]. Arq Gastroenterol, 32(2), 54-65.

Rothstein, R. D. (1990). Gastrointestinal motility disorders in diabetes mellitus. Am J Gastroenterol, 85(7), 782-785.

Rundles, R. W. (1945). Diabetic neuropathy: general views with report of 125 cases. Medicine, 24, 111-160.

Sanmiguel, C. P., Mintchev, M. P., \& Bowes, K. L. (1998). Electrogastrography: a noninvasive technique to evaluate gastric electrical activity. Can J Gastroenterol, 12(6), 423-430.

Schvarcz, E., Palmer, M., Ingberg, C. M., Aman, J., \& Berne, C. (1996). Increased prevalence of upper gastrointestinal symptoms in long-term type 1 diabetes mellitus. Diabet Med, 13(5), 478-481.

Siddique, R., Ricci, J. A., Stewart, W. F., Sloan, S., \& Farup, C. E. (2002). Quality of life in a US national sample of adults with diabetes and motility-related upper gastrointestinal symptoms. Dig Dis Sci, 47(4), 683-689.

Smout, A. J., van der Schee, E. J., \& Grashuis, J. L. (1980). What is measured in electrogastrography? Dig Dis Sci, 25(3), 179-187.

Soykan, I., Lin, Z., Sarosiek, I., \& McCallum, R. W. (1999). Gastric myoelectrical activity, gastric emptying, and correlations with symptoms and fasting blood glucose levels in diabetic patients. Am J Med Sci, 317(4), 226-231. 
Soykan, I., Sivri, B., Sarosiek, I., Kiernan, B., \& McCallum, R. W. (1998). Demography, clinical characteristics, psychological and abuse profiles, treatment, and long-term follow-up of patients with gastroparesis. Dig Dis Sci, 43(11), 2398-2404.

Talley, N. J., Young, L., Bytzer, P., Hammer, J., Leemon, M., Jones, M., et al. (2001). Impact of chronic gastrointestinal symptoms in diabetes mellitus on health-related quality of life. Am J Gastroenterol, 96(1), 71-76.

Thomas, C. (1997). Taber's cyclopedic medical dictionary $\left(18^{\text {th }}\right.$ ed). Philadelphia, PA: FA Davis.

UK Prospective Diabetes Study Group. (1998). Intensive blood glucose control with sulphonylureas or insulin compared with conventional treatment and risk of complications in patients with type 2 diabetes: UKPDS 33. Lancet, 352, 837-853.

Wingate, D. L. \& Phillips, S. F. (1998). Functional disorders of the gut. New York, NY: Churchill Livingston.

Wood, JD. (1998). Physiology of the enteric nervous system. New York, NY: Raven Press.

Woods, N.F. \& Cantanzaro, M. (1988) Nursing research: theory and practice. St. Louis: Mosby 
APPENDIX 


\section{Appendix A \\ Institutional Review Board Approval Letter}


May 15, 2002

Sandra L. Holmes, MSN,RN, APRN

Department of Nursing

College of Nursing

656 Lamar Alexander Building

CAMPUS MAIL

Dear Ms. Holmes:

We are in receipt of your written acceptance of and/or response to the provisos outlined in my letters of March 20, 2002 and April 17, 2002 concerning the project entitled "Gastric Myoelectrical Activity in Patients with Diabetes", (IRB \#7602).

The IRB has reviewed these materials and determined that they do comply with the proper consideration for the rights and welfare of human subjects, the risk involved and the potential benefits of the study. Therefore, this letter constitutes full approval of your application, consent form and advertisements (stamped IRB approved May 15, 2002) from the Institutional Review Board for the above referenced study. This project was approved for 12 months.

In the event volunteers, either subjects or patients, are to be recruited by means other than usual and standard patient care practices, the Board must approve of any such solicitation materials (i.e., advertising copy, posters, etc.).

Any alterations (revisions) in the protocol or consent form must be promptly reported to and approved by the UTHSC Institutional Review Board prior to implementation of these revisions. You have individual responsibility for reporting to the Board in the event of unanticipated or serious adverse events and subject deaths.

In addition, reapproval of your project is required by the IRB, and it is the responsibility of the Principal Investigator to initiate the request for continuation (reapproval) regardless of the time the activity has been approved by the sponsoring agency. Your research project may not continue beyond the schedule as indicated above unless you obtain written approval to continue the project.

Sincerely,

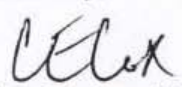

Clair E. Cox, M.D.

Chairman

Institutional Review Board 
Appendix B

Patient Information and Informed Consent Form 


\section{Patient Information and Informed Consent Form}

Research Protocol Gastric Myoelectrical Activity in Patients with Diabetes

Participant's Name

Principle Investigator: $\quad$ Sandra L. Holmes, RN

877 Madison Ave., Rm. 656

Memphis, TN 38163

(901) 448-8277

Co-Investigators: $\quad$ Mona Wicks, $\mathrm{RN}, \mathrm{PhD}$

Donna Hathaway, RN, PhD

Ann Cashion, RN, PhD

\section{Purpose}

You are invited to participate in the research study entitled "Gastric Myoelectrical Activity in Patients with Diabetes". You may be included in this study because you have been diagnosed with diabetes or as a normal healthy control. All participants will undergo the same tests, whether you have diabetes or not, in order to compare results. We know that complications of diabetes, such as eye, kidney, and nerve problems, occur because the body cannot keep normal blood sugar levels. One of the reasons that some people have problems with their blood sugar is because their stomachs do not always work right. When the stomach does not work like it should, the foods or medicines that you take do not breakdown the way that they should. They are also not absorbed by the intestines into the body as they should be. Sometimes symptoms such as nausea, vomiting, stomach pain, lack or loss of appetite, or bloating occur. These symptoms make it hard for the person to eat and take care of him or herself. These problems can also make it harder to keep your blood sugar levels normal. We hope that this study will help us to find out more about how the stomach of a patient with diabetes works. We also hope to learn how we can plan and monitor treatments that will help eliminate problems that cause the stomach to not work well.

This study will use Electrogastrography $(E G G)$ to look at how the stomach works. This piece of equipment works like an electrocardiograph (EKG) of the heart, measuring the electrical activity of the stomach through electrodes (patches) that are placed on the skin. EGG has been proven to be a good test of stomach activity. EGG can be completed quickly, and is tolerated well by patients. We will use EGG in this study to assess stomach function. 
Approximately 125 participants will be enrolled in this study. This number includes 50 patients with type 1 diabetes, 50 patients with type 2 diabetes, and 25 healthy volunteers. The study will be conducted in the Center for Health Evaluation and Lifestyle Promotion (HELP Center) at the University of Tennessee Health Science Center, in Memphis, TN. All of the information required to complete this study will be collected during one conveniently scheduled appointment estimated to last 3-4 hours in the HELP Center.

\section{Procedures}

If you agree to participate in this study, you will be asked to read and sign a copy of this informed consent. You will be asked to give some information about your current health and medical history. You will need to come to the HELP Center to have your stomach test performed after fasting for at least 8 hours, and answer some questions about the kind and severity of stomach symptoms that you experience. You will also have blood samples taken from a large vein in your arm or back of the hand.

\section{Gastric (Stomach) Function Test}

The stomach test that you will have is called Electrogastrography (EGG). This test detects the electrical activity of the stomach that controls the movements of the stomach. The test is like the electrocardiogram $(\mathrm{EKG})$ used to monitor the heart. For this test, you will have EKG electrodes (patches) applied to your stomach. Alcohol may be used to clean your skin and stomach hair may need to be shaved. You will wear the EGG monitor for approximately 2 hours. The first 30 minutes will be used to record baseline activity. After thirty minutes, you will be provided with a standard meal (egg, toast, milk) to eat. During the meal, and for the next $1 \frac{1 / 2}{2}$ hours, you will be monitored.

\section{Symptom Assessment}

You will be asked about the kind and severity of stomach symptoms (nausea, vomiting, stomach pain, lack or loss of appetite, and bloating) that you have experienced. A short questionnaire will be used to assess symptoms that you have experienced over the past 2 months. You will be asked before eating, and every 30 minutes after you complete your meal, to rate any stomach symptoms that you have during the EGG test.

\section{Blood Sampling}

You will have 10 milliliters (approximately 2 teaspoonfuls) of blood drawn by an experienced laboratory technician to assess the level of blood sugar control that you have maintained over the past 2 months. You will also have fingerstick blood sugar testing performed prior to beginning EGG data collection, immediately before serving the test meal, and every 30 minutes after eating the meal until the end of the testing procedure. You may have blood drawn from an alternate site such as your forearm for your blood sugar test if you chose to do so. 


\section{Risk Associated with Participation}

You understand that there will be minimal potential risk during your participation in this study. Some individuals experience skin irritation while wearing the patches and pain or bruising with the venipuncture that is required for obtaining blood specimens. You will be referred to your personal physician or to the Acute Receiving Area (ARA) at UT Bowld Hospital if any troubling symptoms develop during testing. You will be asked to treat too low or too high blood sugar levels as you normally do based upon your current treatment plan or schedule. Any new information obtained during this study that will affect your willingness to participate in this study will be provided to you.

\section{Benefits Associated with Participation}

There are no direct benefits from participating in this research study. Potential benefits that you may obtain from this study are: 1) assessment of stomach activity, 2) identification of factors that may interfere with your ability to keep up blood sugar control, 3) assessment of stomach symptoms, and 4) evaluation of metabolic control. Information about changes in your health brought about by diabetes may help healthcare providers to find new ways to improve the health and lives of other patients.

\section{Alternative to Participation}

The alternative to participating in this study is to not participate and thereby not have to undergo any testing.

\section{Confidentiality}

You have the right to privacy. All information that you provide, including medical history, questionnaires, laboratory findings, and physical examination will be kept confidential. The information obtained will not be released to your primary care provider, placed in your medical records, or released to any other entity without your written permission. However, representatives of the University of Tennessee Health Science Center Institutional Review Board and representatives of the United States Food and Drug Administration (FDA) may access confidential records from this study.

Code numbers will be assigned to all data derived from this study and all information containing your name or other identifying information will be stored in a locked file cabinet and on a personal computer. The master key linking code will be maintained in a separate secure location. Only the research team will have access to this information. The data collected during this study will be used in reports, presentations, and publications, but you will not be individually identified unless your written express consent to reveal your identity is given.

\section{Compensation and Treatment for Injury}

Every reasonable precaution will be taken to ensure your safety during the course of this study. In the event that this research activity results in an injury, treatment will be available, including the first aid, emergency treatment, and follow-up care as 
needed. Payment for any such treatment must be provided by you or your third party payer, if any, such as insurance or Medicare.

My signature on this form confirms that I understand that I am not waiving any legal rights or releasing the University of Tennessee of its agents from liability or negligence. I understand that, in the event of physical injury resulting from the research procedure, the University of Tennessee does not have funds budgeted for compensation either for lost wages or for my medical treatment. Therefore, the University does not provide for treatment or for reimbursement for such injuries. I am aware that I may withdraw my consent to participate at any time and that such withdrawal will not restrict my access to healthcare services normally available at the University of Tennessee.

\section{Questions}

If you have any questions or feel that you have sustained any injury as a result of this study please contact Sandra Holmes (901-448-8277 or 877-346-6164 \{24-hour pager $\}$ ) or the HELP Center (901-448-1584). If I have any questions regarding my rights as research subject in this study, I may call the University of Tennessee Health Science Center's Institutional Review Board Chair, Clair E. Cox, MD (901-4484824). My signature below means that I have freely agreed to participate in this study and I have received a copy of this consent form for my records.

\section{Payment for Participation}

I will be paid $\$ 25.00$ for completing this study. Payment will not be rendered if I do not complete all parts of the research protocol. If I am a minor, payment will be made to me in care of my parent or guardian.

\section{Cost of Participation}

I will incur no charges for participating in this study. The investigator will provide funds to pay for all services required for completion of this study.

\section{Premature Termination}

In the event that I decide not to participate in this study, I will notify Ms. Holmes. I understand that I may withdraw from the study at any time and will continue to receive standard treatment.

\section{Voluntary Participation}

I understand that I am not required to participate in this study and that I a free to refuse to participate in the study or withdraw from the study at any time. My decisions will not affect my care at this institution and I will not be penalized or lose any benefits to which I am entitled.

\section{Consent of Subject}

I have read or have had read to me the description of the study as outlined above. The investigator or his/her representative has explained the study to me and has answered all of the questions I have at this time. I have been told of the potential risk, 
discomforts, side effects, and adverse reactions, as well as the possible benefits (if any) of the study. I freely volunteer to participate in this study. I understand that I do not have to take part in this study and that my refusal to participate will involve no penalty or loss of rights to which I am entitled. I further understand that I am free to withdraw from this study at any time. I understand that refusing to participate or later withdrawing from this study will not adversely affect the subsequent medical care that I receive.

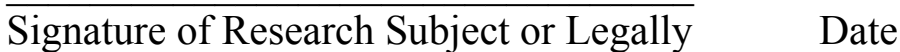
Authorized Representative

Signature of Witness

Date

Signature of Person Obtaining Consent

Date

Signature of Principal Investigator

Date

Assent of Minor

Date 
Appendix C

Patient Data Sheet 


\section{Patient Data Sheet}

EGG Study

Date

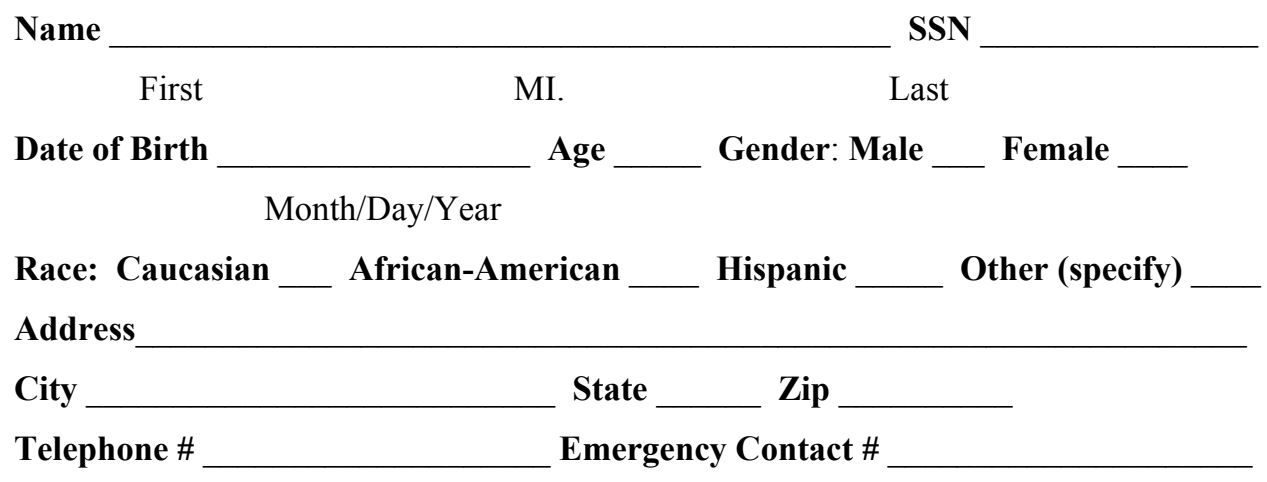

Marital Status: Single ___ Married ___ Divorced __ Widow(er)

Highest Level of Education (circle one): Grade $<6 \quad 6 \quad 7 \quad 891011 \quad 12$ College 12234 + Degrees

Employment Status: Fulltime __ Part-time __ Retired __ Disabled _ Unemployed

Occupation

Smoke? Y N Number of cigarettes per day _ Number of Years _ _ Pack/Years

Allergies?

Do you have or have you had any of the following diseases or conditions:

High Blood Pressure

Stroke Heart Attack

Angina Heart Failure Sickle Cell Disease

Cancer Kidney Problems Lung Problems

Bleeding Problems ___ Liver Problems Psychiatric Problems

Seizures Peptic Ulcer Disease Gastroesophageal Reflux Disease

Pancreatitis Uremia Crohn's Disease Ulcerative Colitis Irritable Bowel Disease Lactose Intolerance Anorexia Nervosa

Bulimia Type 1 Diabetes

Type 2 Diabetes

Years DM Age at Diagnosis Last Menstrual Period

Current Medications

HT WT BP Time of Last Meal Fasting Blood Glucose 
Appendix D

Flow Diagram of Testing Procedure 


\section{Flow Diagram of Testing Procedure}

\section{Participant recruited}

Study reviewed and testing date scheduled

Testing Day

Verify fasting status, taking of regularly prescribed meds (except GI meds previously indicated)

Obtained informed consent

Collect demographic data, complete symptom assessment (TSS), obtain blood sample

\begin{tabular}{|c|}
\hline Perform blood glucose monitoring \\
\hline Direct to restroom \\
\hline Positioned in recliner \\
\hline Complete symptom assessment (VAS) \\
\hline EGG electrodes attached \\
\hline Record EGG in fasting state for 30 minutes \\
\hline Perform blood glucose monitoring \\
\hline Complete symptom assessment (VAS) \\
\hline Provide meal \\
\hline Record first post-prandial period ( 30 minutes) \\
\hline Perform blood glucose monitoring \\
\hline Complete symptom assessment (VAS) \\
\hline Record second post-prandial period \\
\hline Perform blood glucose monitoring \\
\hline Complete symptom assessment (VAS) \\
\hline Record third post-prandial period \\
\hline Perform blood glucose monitoring \\
\hline Complete symptom assessment (VAS) \\
\hline
\end{tabular}


Appendix E

Visual Analog Scales 
Study Number

\section{VAS}

VAS\#:

Time:

Comments:

VAS Scale:

Worst Possible Nausea $\quad 100$

No Nausea

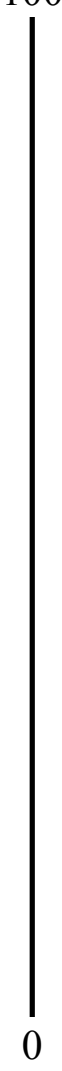


Study Number

\section{VAS}

VAS\#:

Time:

Comments:

VAS Scale:

Worst Possible Bloating $\quad 100$

No Bloating

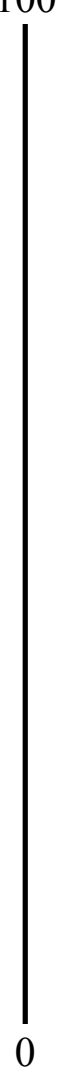


Study Number

\section{VAS}

VAS\#:

Time:

Comments:

VAS Scale:

Worst Possible Vomiting $\quad 100$

No Vomiting

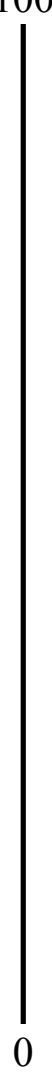


Study Number

\section{VAS}

VAS\#:

Time:

Comments:

VAS Scale:

Worst Possible Pain $\quad 100$

No Pain 
Study Number

\section{VAS}

VAS\#:

Time:

Comments:

VAS Scale:

Worst Possible Satiety $\quad 100$

No Satiety 
Study Number

\section{VAS}

VAS\#:

Time:

Comments:

VAS Scale:

Worst Possible Anorexia $\quad 100$

No Anorexia

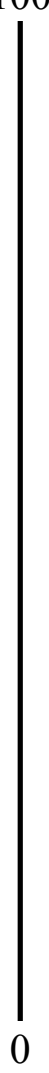


Appendix F

Total Symptom Scale 


\section{UT/UTMG “GI” Symptom Scale}

Project: Gastric Myoelectrical Activity in Patients with Diabetes

Study Number:

Date:

The Investigator ask the patient for the overall intensity of each listed symptom on a scale of $0-10$, where 0 is best and 10 is worst.

\begin{tabular}{|c|c|c|c|}
\hline Symptom & No & Yes & $\begin{array}{lr}\text { Best } & \text { Worst } \\
& \text { Circle ONE Number }\end{array}$ \\
\hline $\begin{array}{l}\text { Did the patient have } \\
\text { Nausea (feel sick to } \\
\text { His/her stomach)? }\end{array}$ & & & $\begin{array}{lllllllllll}0 & 1 & 2 & 3 & 4 & 5 & 6 & 7 & 8 & 9 & 10\end{array}$ \\
\hline $\begin{array}{l}\text { Did the patient have } \\
\text { Bloating/distention } \\
\text { (loosen clothes after } \\
\text { eating)? }\end{array}$ & & 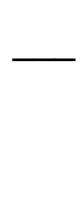 & $\begin{array}{lllllllllll}0 & 1 & 2 & 3 & 4 & 5 & 6 & 7 & 8 & 9 & 10\end{array}$ \\
\hline $\begin{array}{l}\text { Did the patient have } \\
\text { Anorexia (poor appetite)? }\end{array}$ & & & $\begin{array}{lllllllllll}0 & 1 & 2 & 3 & 4 & 5 & 6 & 7 & 8 & 9 & 10\end{array}$ \\
\hline $\begin{array}{l}\text { Did the patient have } \\
\text { Abdominal Pain? }\end{array}$ & & & $\begin{array}{lllllllllll}0 & 1 & 2 & 3 & 4 & 5 & 6 & 7 & 8 & 9 & 10\end{array}$ \\
\hline $\begin{array}{l}\text { Did the patient have } \\
\text { Satiety (feel full } \\
\text { early)? }\end{array}$ & 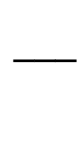 & & $\begin{array}{lllllllllll}0 & 1 & 2 & 3 & 4 & 5 & 6 & 7 & 8 & 9 & 10\end{array}$ \\
\hline
\end{tabular}

OVERALL PATIENT ASSESSMENT

On a 0 1- scale, how

did the patient feel

during the past 2

months overall? 


\section{VITA}

Sandra Luberata Holmes was born in 1966 in Greenwood, Mississippi, and raised in nearby Itta Bena. She received a Bachelor of Science degree in Biology from Mississippi Valley State University in Itta Bena in 1987. She attended Methodist Hospital School of Nursing in Memphis, TN and graduated with a diploma in Nursing in May of 1992. In May of 1996, she graduated from Memphis State University with a Bachelor of Science degree in Nursing. She completed requirements for a Master of Science degree in Nursing with a concentration in Medical-Surgical Nursing from the University of Tennessee Health Science Center in 1999.

Ms. Holmes entered the Doctor of Philosophy in Nursing program at the University of Tennessee Health Science Center in June of 1999. She is a member of several professional organizations including Sigma Theta Tau International Nursing Honor Society, American Nurses Association, Tennessee Nurses Association, National Association of Bariatric Nurses, National Black Nurses Association, Academy of Medical-Surgical Nurses, and Southern Nurses Research Society. Her dissertation research focused on consequences of abnormal gastric motility in persons with diabetes mellitus. She received a Doctor of Philosophy degree with a nursing focus in May 2007. She is employed as an Advance Practice Nurse. 